\title{
The Lunar Mare Ring-Moat Dome Structure (RMDS) Age Conundrum: Contemporaneous with Imbrian-Aged Host Lava Flows or Emplaced in the Copernican?
}

Feng Zhang ${ }^{1,2}$, James W. Head ${ }^{3}$, Christian Wöhler ${ }^{4}$, Alexander T. Basilevsky ${ }^{5}$, Lionel Wilson $^{6}$, Minggang Xie ${ }^{7}$, Roberto Bugiolacchi ${ }^{2}$, Thorsten Wilhelm ${ }^{4}$, Stephanie Althoff $^{4}$, and Yong L. Zou ${ }^{1}$

${ }^{1}$ State Key Laboratory of Space Weather, National Space Science Center, Chinese Academy of Sciences, Beijing, China; ${ }^{2}$ State Key Laboratory of Lunar and Planetary Sciences, Macau University of Science and Technology, Macau, China; ${ }^{3}$ Department of Earth, Environmental and Planetary Sciences, Brown University, Providence, RI, USA; ${ }^{4}$ Image Analysis Group, TU Dortmund University, Dortmund, Germany; ${ }^{5}$ Vernadsky Institute of Geochemistry and Analytical Chemistry, Russian Academy of Sciences, Moscow, Russia; ${ }^{6}$ Lancaster Environment Centre, Lancaster University, Lancaster, UK; ${ }^{7}$ College of Science, Guilin University of Technology, Guilin, China

Corresponding Author: F. Zhang (zhangfeng@nssc.ac.cn)

\section{Key Points:}

(1) Clusters of unusual features, Ring Moat Dome Structures (RMDSs), occur extensively in the lunar maria

(2) Multiple lines of evidence suggest two alternative origins, contemporaneous with Imbrian flows, or later, in the Copernican

(3) We list outstanding questions and suggest future research and exploration scenarios to resolve the age conundrum

\section{Abstract \\ Ring-Moat Dome Structures (RMDSs) are small circular mounds of diameter} typically about $200 \mathrm{~m}$ and $\sim 3-4 \mathrm{~m}$ in height, surrounded by narrow, shallow moats. They occur in clusters, are widespread in ancient Imbrian-aged mare basalt host units and show mineralogies comparable to those of their host units. Based on these close associations and similarities, a model has been proposed for the formation of RMDS as the result of late-stage flow inflation, with second boiling releasing quantities of 

magmatic volatiles that migrate to the top of the flow as magmatic foams and extrude through cracks in the cooled upper part of the flow to produce the small RMDS domes and surrounding moats. In contrast to this model advocating a contemporaneous emplacement of RMDSs and their host lava flows, a range of observations suggests that the RMDS formed significantly after the emplacement and cooling of their host lava flows, perhaps as recently as in the Copernican Period $(\sim 1.1$ Ga to the present). These observations include: 1) stratigraphic embayment of domes into post-lava flow emplacement impact craters; 2) young crater degradation age estimates for the underlying embayed craters; 3) regolith development models that predict thicknesses in excess of the observed topography of domes and moats; 4) landform diffusional degradation models that predict very young ages for mounds and moats; 5) suggestions of fewer superposed craters on the mounds than on the adjacent host lava flows, and 6) observations of superposed craters that suggest that the mound substrate does not have the properties predicted by the magmatic foam model. Together, these observations are consistent with the RMDS formation occurring during the period after the extrusion and solidification of the host lava flows, up to and including the geologically recent Late Copernican, i.e., the last few hundreds of millions of years of lunar history. We present and discuss each of these contradictory data and interpretations and summarize the requirements for magma ascent and eruption models that might account for young RMDS ages. We conclude with a discussion of the tests and future research and exploration that might help resolve the 
RMDS age and mode of emplacement conundrum.

\section{Plain Language Summary}

The research reported in this paper provides multiple lines of evidence for the discovery of very young mare volcanism on the Moon, thus extending the lunar volcanic history into the Copernican period ( $\sim 1.1$ Ga to present). Current lunar thermal evolution models have placed an upper limit for the cessation of large-scale mare volcanism at $\sim 2.0 \mathrm{Ga}$ ago. In this study, we used both morphometric analysis and topographic diffusion models to date some small craters (100-300 $\mathrm{m}$ in scale) which are partially overlapped by ring-moat dome structures (RMDSs, basaltic lava flow surface features characterized by a domical profile encircled by a ring moat).

Our results lead to a conclusion that lunar mare volcanism accounting for the emplacement of these RMDS-bearing basalts may have occurred several hundreds of millions of years ago (i.e., 130-1500 Ma), thus challenging the present consensus on the thermal history of the Moon. To address this issue, we also list a series of outstanding questions and robotic/human exploration strategies that could provide conclusive evidence for or against our hypotheses, thus increasing our understanding of the duration and flux of lunar volcanism and the thermal evolution of the Moon.

\section{Introduction}

A major outstanding question in the evolution of the Moon is the onset, duration and flux of lunar mare volcanism, and its contribution to the building of the lunar secondary crust. The study of lunar meteorites shows that volcanism started early in the history of the Moon (> $4 \mathrm{Ga}$ ) (Borg et al., 2015; Taylor et al., 1983; Terada et al., 
79 2007); however, much less consensus has been reached on the time of cessation of

80 extrusive activities. This is not a secondary issue: a reliable timeline would constrain

81 our current models of the thermal and compositional evolution of the Moon (e.g.,

82 Head, 1976; Hess \& Parmentier, 1995; Solomon, 1978, 1986; Wieczorek et al., 2006).

83 Returned lunar samples indicate that the bulk of mare volcanism was confined to the

84 interval of 3.8 to 3.1 Ga years ago, with major volcanic eruptions peaking in the

85 Imbrian period (3.8-3.2 Ga ago; Head \& Wilson, 2017; Hiesinger et al., 2011). The

86 youngest ages of lunar mare volcanism have been reported in the range of $\sim 2.9 / 2.5 \mathrm{Ga}$

87 from the study of lunar meteorites (Borg et al., 2004; Fernandes et al., 2007), and, by

88 inference, as young as $1.2 \mathrm{Ga}$ from crater chronology approaches based on the

89 comparison with lunar chronology functions (Hiesinger et al., 2011; Schultz \& Spudis,

90 1983). Even younger ages of $\sim 10$ Ma relating to the Ina structure (Schultz et al., 2006)

91 and $<100$ Ma for Ina-like irregular mare patches (IMPs) (Braden et al., 2014) have

92 been put forward based on this indirect approach. However, Ina and its surrounding

93 mare are compositionally identical (Bennett et al., 2015), making the likelihood of

94 being geologically contemporaneous most likely (Garry et al., 2012; Qiao et al., 2017;

95 Wilson \& Head, 2017b). Furthermore, the use of small craters (e.g., $<200 \mathrm{~m}$ ) to date

96 geographically small mare surfaces remains controversial (McEwen \& Bierhaus, 2006;

97 Williams et al., 2018). Consequently, the evidence in support of Copernican-aged

98 mare volcanism younger than $\sim 1.0 \mathrm{Ga}$ is weak.

99 Recent comprehensive surveys have revealed the widespread distribution of Ring 
100

Moat Dome Structures (RMDSs), which are lunar morphological features

101 characterized by a relatively low, circular topography surrounded by a shallow moat.

102 Their composition does not differ from the local mare in which they occur (their host

103 unit) and they tend to occur in clusters in a wide range of mare settings (Zhang et al.,

$1042017,2018,2020)$. A theoretical model of their formation (Wilson et al., 2019), based

105 on their comprehensive characterization (Zhang et al., 2017, 2020), suggests that

106 RMDSs represent extrusive features linked to the emplacement of the host basaltic

107 lava flows. Accordingly, they would have formed during late-stage inflation-related

108 emplacement processes of the flow, including second boiling, segregation of

109 vesicle-rich magma within the flow, and its extrusion to the surface to produce the

110 RMDS features. This model supports the contemporary formation of RMDSs and

111 associated flows (most >3.0 Ga; Hiesinger et al., 2011). However, the superposition

112 relationships of some RMDSs on small, degraded craters $<300 \mathrm{~m}$ in diameter suggests

113 a very young age, in the order of hundreds of Ma (Basilevsky et al., 2019; Zhang et al.,

114 2020). This would place the formation of some RMDSs within the Copernican era,

115 billions of years after the emplacement of most mare basalts. Such young ages

116 conflict with the previous RMDS models (Wilson et al., 2019; Zhang et al., 2017).

117 In this contribution, we first briefly outline the nature of RMDSs and the

118 hypothesis that suggests that they formed more than several billion years ago,

119 contemporaneously with their host mare units, and then we present multiple lines of

120 evidence that appear to contradict this model, and that together suggest that the 
121 RMDS formed much later than their host lava flows, in the recent Copernican period

122 of lunar history. We then synthesize the evidence for Copernican-aged RMDS

123 formation and translate this into the requirements for any successful model for the

124 generation, ascent, and eruption of magma to explain the Copernican-aged formation

125 of RMDS. Finally, we list a series of outstanding questions and robotic/human

126 exploration strategies that can provide definitive evidence to resolve the RMDS age

127 conundrum and thus increase our understanding of the duration and flux of lunar

128 volcanism and the thermal evolution of the Moon.

129

130 2. RMDS Characteristics and Distribution

131 Mound-like features with surrounding moats were first identified in Lunar

132 Orbiter image data and described by Schultz and Greeley (1976) and Schultz et al.

133 (1976) and later found in much more abundance in Lunar Reconnaissance Orbiter

134 (LRO) image data and named ring-moat dome structures (RMDSs) (Zhang et al.,

135 2017). Following this, Zhang et al. (2020) reported on a much more comprehensive

136 analysis of the nature and distribution of RMDSs, summarized here. They found that

137 the positive morphologic RMDS features occurred in clusters in many lunar mare

138 regions, most of which had not been previously reported, and they expanded the

139 known RMDS locations from $\sim 2,600$ to over 8,000 (yellow crosses, Figure 1). Zhang

140 et al. (2020) presented a detailed analysis of over 500 RMDSs located in several

141 different mare basins, combining elemental mapping, morphology and morphometry,

142 distribution relationships, and relationships with other geologic structures. They also 
143 assessed numerous terrestrial analogs to the RMDS features. They concluded that the

144 RMDS can be characterized as follow:

145 1) They are low circular mounds a few hundred meters in diameter (average

$146 \sim 200 \mathrm{~m}$ ) with a mean height of $3.5 \mathrm{~m}$.

147 2) Mounds are surrounded by moats ranging from tens to over $200 \mathrm{~m}$ wide and

148 up to several meters deep.

149 3) They are more commonly found in moderate-to-high $>3 \mathrm{wt} \% \mathrm{TiO}_{2}$ mare units,

150 though a wide titanium abundance variation is observed.

151 4) They are found in spatial association with lava flow units and sometimes with

152 associated volcanic-related features (e.g., Head \& Wilson, 2017), such as small

153 shields and cones (Zhang et al., 2020, their Figure 16).

154 5) Some but not all display some spatial associations with Irregular Mare Patches

155 (see Braden et al., 2014), leading Zhang et al. (2020) to suggest that both may form

156 from related lava flows.

157 6) Zhang et al. (2020) found a favorable comparison between lava inflationary

158 structures on Earth and RMDSs, lending support to a hypothesis of an origin

159 involving inflation-related extrusive volcanism and a genetic relationship of RMDSs

160 with host lava flow emplacement processes.

161 7) Zhang et al. (2020) noted embayment relationships between some RMDS

162 mounds and craters of apparent impact origin (and of different degradation states)

163 superposed on the host mare. They concluded that these examples conflicted with 
164 RMDS formation models in which RMDSs formed contemporaneously with their host

165 lava flows.

166 Zhang et al. (2020) thus outlined two conflicting models for RMDS formation: a)

167 Synchronous with the emplacement and cooling of their ancient host lava flows $(\sim 3-4$

168 Ga old), and b) substantially postdating the emplacement and cooling of the host mare

169 lava unit, likely some time during the Copernican and/or Eratosthenian periods $(\sim 0-3$

170 Ga old).

171

172 3. The Model for Contemporaneous Host Lava Flow-RMDS Formation

173 This hypothesis was initially proposed by Zhang et al. (2017) and then described

174 in detail by Wilson et al. (2019) based on a theoretical model of lava flow

175 emplacement and cooling behavior. Wilson et al. (2019) used descriptions and

176 preliminary interpretations of RMDSs and models of the dynamics of lunar lava flows

177 (Head \& Wilson, 2017; Wilson \& Head, 2017a) to try to account for the major

178 characteristics of RMDSs (Zhang et al., 2017, 2018, 2020). A summary of the model

179 is as follows: in the early stages of an eruption of mare basalt, the magma contains

180 very low quantities of dissolved volatiles and a few exsolved gas bubbles because

181 these have been largely and efficiently lost during the pyroclastic hawaiian fire

182 fountain activity at the vent. The lava flow surface and base cool progressively as the

183 lava travels away from the vent, resulting in upper and lower solidified boundary

184 layers and a molten core. Toward the end of the eruption at the vent, magma rise

185 speed in the dike decreases as dike closure begins. This lowering of magma ascent 
186

187

188

189

190

191

192

193

194

195

196

197 Consequently, in turn, crustal fractures are created permitting the extrusion of

198

199 The result is the extrusion of the magmatic foam through the cracks to form the

200 circular dome-like mounds on the surface. The extrusion is accompanied by

201 subsidence of the surrounding surface and the solid crust below the extruded mound,

202 in response to displacement of the foam. This subsidence is interpreted to form the

203 ring moats surrounding the mounds.

204

rate enhances the ability of gas bubbles to form and coalesce, favoring strombolian activity at the vent, which removes some gas but leaves residual volatiles in solution. Magma from this phase of the eruption is then injected into the previously emplaced molten flow core causing flow inflation and resulting in substantial uplift of the flow surface. Eventually, the flow comes to a halt with the now volatile-rich inflated magma core. As the lava cools in place, it begins to crystallize, leading to supersaturation of the residual dissolved volatiles that remain in the injected flow core. This second boiling generates exsolved gas that produces massive quantities of vesicles, both at the top and bottom of the cooling central flow core. This results in the production of very vesicular to foamy layers, accompanied by further flow inflation of many meters, and causing flexing of the cooled upper crustal layer. magmatic foams onto the surface, driven by the buoyancy of the vesicle-rich magma. ring moats surtounding the mounds.

Second boiling and inflation are commonly seen in many large basaltic flows on Earth, but RMDS formation should be facilitated on the Moon in all lava flows greater than $\sim 50 \mathrm{~km}$ length and thicknesses more than $\sim 10$ m by several factors: 1 ) 
207 lunar basalts have low viscosity compared with terrestrial ones; 2) the predicted high

208 effusion rates in typical lunar eruptions; and crucially, 3) the lack of a lunar

209 atmosphere. Furthermore, the formation of extremely vesicular foams (the

210 consequence of low lunar gravity and absence of an atmosphere), is unique to the

211 lunar environment and permits both upward flexing and fracture of the upper thermal

212 boundary layer surface of the lava flow, and the extrusion of the foam to form the

213 distinctive RMDS mounds.

214 The RMDS emplacement model of Wilson et al. (2009) outlined above (see

215 synthesis in their Figure 5) is characterized by numerous implications that could be

216 formulated as hypotheses to be tested in future studies and exploration to assess,

217 discard, or modify:

218 1) Shape of Domes: Foam extrusion from cracks in the uplifted summit of the

219 underlying lava flow crust should generally lead to near circular-shaped domes. This

220 is because the final radius of the dome is likely to be significantly greater than the

221 linear extent of the fracture in the lava crust through which the foam is extruded; the

222 non-Newtonian rheology of the foam, specifically its yield strength, means that its

223 lateral spread is driven by the vertical accumulation of the bulk foam mass rather than

224 the detailed shape of the fracture.

225 2) Size Variability of Individual Domes and Their Moats: The formation process

226 of domes involves the redistribution of a volume of vesicular lava from the lava flow

227 interior onto its surface. The material will undergo a change in its bulk density upon 
228 emplacement, but the overall volume change and its variability should be small, and

229 the volumes of each dome and its surrounding moat should be similar.

230 3) Variations in RMDS Shape: It has been shown that lava flow surface

231 topography can vary in height by several meters over tens of meters horizontal scales

232 (Kreslavsky et al., 2017) caused by the flow encountering earlier flows or pre-flow

233 impact craters during its emplacement. Asymmetry in RMDS shape and alignment

234 could be due to the intruding lava responsible for some RMDS extrusions diverting

235 around high points or flowing preferentially into elongate topographic lows. Careful

236 analysis of any such irregularities in RMDS clusters could lead to a better

237 understanding of the host flow emplacement and evolution process.

4) RMDS Alignment: Patterns of linearity and alignment of individual RMDSs

239 might be anticipated due either to fractures in distal flows caused by a) unusually

240 extensive pre-eruption topographic variations or b) major internal magma pathways

241 formed during late-stage inflation and second boiling. Such linear patterns should be

242 investigated in further analysis of individual RMDS clusters.

243 5) Immediate Post-Emplacement Deformation of Domes: The second boiling

244 process that leads to RMDS formation occurs in a lava flow that has come to a halt

245 and is cooling and solidifying, and thus RMDSs are predicted not to show any

246 deformation by shearing due to any lateral flow movement.

6) Composition/Mineralogy of Domes and Host Lava Flows: The basic

248 composition and mineralogy of the domes and the host lava flows should be very 
249 similar, but the domes themselves should contain a higher proportion of glass shards

250 due to the fragmentation of the magma emerging from the surface crack at the start of

251 dome growth.

252 7) Nature of Dome Material: RMDS dome material is predicted to be a basaltic

253 lava foam characterized by a vesicularity of $\sim 50-60 \%$. This range is dictated by the

254 requirement that to explain the dome morphology the foam must have a vesicularity

255 that is large enough ( $>30-40 \%)$ to ensure a significant yield strength and viscosity, but

256 is small enough $(<\sim 75 \%)$ to ensure that the foam does not disintegrate under shearing

257 forces.

258 8) Initial Upper Layer of Dome Material: Dome material should be overlain by

259 an "autoregolith", a layer of shattered foam caused by eruption into a vacuum,

260 composed of a mixture of loosely packed glass shards and chilled magma droplets up

261 to a few meters-thick and with $\sim 30 \%$ void space, the amount expected for any

262 unwelded accumulation of irregular brittle fragments.

263 9) Dome Stratigraphy and Regolith Development: What is the "regolith protolith"

264 (Head \& Wilson, 2020) of the domes, the stratigraphy of the substrate immediately

265 following their emplacement? The Wilson et al. (2019) model predicts that the

266 regolith protolith stratigraphy will consist of an upper layer of "autoregolith" up to

267 several meters thick, overlying a layer of very vesicular $(\sim 50-60 \%)$ foamy basalt,

268 with this in turn overlying the upper chilled thermal boundary layer of the initially

269 emplaced RMDS-host lava flow. There are uncertainties in both the thickness of the 
270 extruded vesicular/foamy lava and the topography of the underlying solid basalt flow

271 top. Wilson et al. (2019) considered two models for the topography of the underlying

272 host basalt layer, one in which it was uplifted (favoring shedding of the extruded

273 vesicular/foam layer and solid lava flow exposure nearer the dome summit) and one

274 in which it subsided (favoring thickening of the vesicular/foam layer near the mound

275 summit).

276 10) Predicted Nature of Post-Mound Impact Craters: Subsequent superposed

277 impact craters should initially encounter an autoregolith layer up to several meters

278 thick; small craters should look very similar to those in mature regolith with few to no

279 associated boulders. Larger craters should penetrate to the vesicular/foam layer and

280 their shape could be influenced by the amount of vesicularity; foamy lavas are

281 predicted to behave more like an aerogel, with energy partitioning favoring crushing

282 over ejection, with associated effects on crater depth and shape, perhaps producing

283 narrower, dimple like structures in this part of the target substrate. Even larger craters

284 will penetrate the uplifted (or sagged) top of the host lava flow and thus should look

285 like normal craters superposed on the adjacent host lava flows. Careful analysis of this

286 range of crater sizes could lead to both a testing of the hypothesis and an improved

287 understanding of the actual emplacement processes and resulting stratigraphy.

288 11) Predicted Nature of Post-Moat Impact Craters: The RMDS moat marks the

289 boundary between the extruded dome and the approximate edge of the uplifted or

290 sagged host lava flow upper layer. Therefore, at and inside the moat, the stratigraphy 
291 should be that of the dome, as described above. This should lie in contrast to the

292 substrate characteristics at and outside the moat, which would be dominated by the

293 regolith protolith of the upper solid host mare basalt layer. Impact craters that are

294 superposed on the RMDS boundary are predicted to reflect these differences in

295 RMDS and host-basalt substrates. The portion of the superposed crater in the

296 host-basalt substrate should appear similar to a normal mare basalt regolith crater, but

297 the portion of the superposed crater in the dome material should be much less distinct,

298 with a poorly formed rim crest and ejecta deposit due to the unusual nature of the

299 initial autoregolith and extruded vesicular/foam layer. These contrasting

300 characteristics should be further enhanced by the potential downslope movement of

301 fragmental dome material due to the somewhat steeper slopes of the dome flanks.

302

12) Predicted Differences Between Post-RMDS and Post-Host Mare Basalt Flow

303 Impact Craters: Potentially, the morphology and morphometry of impact craters

304 superposed on the host mare basalt substrate and the domes could be used as a

305 first-order test of the Wilson et al. (2019) extruded vesicular/foam layer hypothesis for

306 the origin of RMDSs. This test is made more difficult, however, by the complex mode

307 of emplacement and autoregolith formation, as well as the uncertainty in the uplift and

308 sagging of the host basalt surface underlying the domes. Very careful analysis of these

309 superposed craters based on the criteria outlined above can serve to test the hypothesis

310 further and even potentially derive an improved understanding of the model

311 uncertainties. 
13) Further Tests of the Flow Inflation/Second Boiling RMDS Model: A

313 characteristic of the Wilson et al. (2019) extruded vesicular/foam layer hypothesis for

314 the origin of RMDSs is that the host flow substrate consists of a highly vesicular lava

315 flow core underlying the upper cooled layer of the mare basalt flow, and that the

316 deformation of this layer led to the extrusion of parts of this core to produce the

317 RMDSs. Implicit in this interpretation is the fact that the interior of the flow could

318 have a very high micro- and macro-porosity remaining upon cooling and

319 solidification, thus consisting of potential void spaces, particularly where the solid

320 basalt layer has been fractured and tilted and the magma below the upper layer has

321 been extruded. In a somewhat analogous case of a small shield volcano late-stage

322 summit crater evolution at Ina, Qiao et al. (2019) and Wilson et al. (2019) have called

323 upon such macroporosity to enhance regolith drainage into the underlining voids to

324 explain similar mound-moat relationships.

325 However, detailed mapping of the relationship of RMDSs to the host mare basalt

326 substrate has revealed examples where individual RMDSs appear to embay circular

327 depressions in the host substrate (Basilevsky et al., 2019). The superposition of

328 RMDSs over craters (RMDS-crater-overlap) suggests that the specific

329 crater-embaying RMDSs may be younger than both the mare substrate and the crater,

330 pointing to an extended time (of unknown duration) that might have occurred between

331 the host mare basalt substrate emplacement and the formation of the domes. This

332 study thus aims to use both morphometric analysis and a topographic diffusion model 
333 to date some small craters (100-300 $\mathrm{m}$ in scale) which are partially overlapped by

334 RMDSs (Figures 2 and 3). Our results show that the emplacement of this

335 RMDS-related volcanism may have occurred up to several hundreds of millions of

336 years ago (i.e., 130-1500 Ma), thus challenging the present consensus on the thermal

337 evolution model of the Moon, which places an upper limit for the cessation of mare

338 volcanism at $\sim 2.0 \mathrm{Ga}$ ago (e.g., Spohn et al., 2001; Ziethe et al., 2009).

339

340

\section{Data and Methods}

The high-resolution Lunar Reconnaissance Orbiter Camera (LROC) NAC

342 images (Robinson et al., 2010) at $0.42-1.5 \mathrm{~m} / \mathrm{px}$ (to date the highest spatial resolution

343 available from lunar orbit), and $2 \mathrm{~m} / \mathrm{px}$ NAC-based DTMs constructed using shading

344 method (see the detail by Zhang et al. (2020) and references therein) were used in this

345 study. All the raw and calibrated NAC image data are accessible via the NASA

346 Planetary Data System (PDS), and calibrated and projected using the USGS ISIS

347 software. These images were then investigated using the software ArcGIS 10.6. We

348 relied on the comprehensive analysis of the distribution and characterization of

349 RMDSs as outlined in Zhang et al. (2020).

350

\section{$351 \quad 4.1$ Age Estimation from Crater Morphometry}

352 The ages of the craters superposed by RMDSs, which are relatively younger, can

353 be estimated based on crater morphology, morphometry, and size relations

354 (Basilevsky, 1976). The RMDS heights (h), height/diameter ratios (h/D) and

355 maximum steepness of their slopes $(\beta)$, as well as the crater depths $(\mathrm{d})$, depth/diameter 
ratios $(d / D)$ and maximum steepness of inner slopes $(\alpha)$ were measured from

NAC-based DTMs. For impact craters, these parameters allow us to approximately estimate their absolute ages (Basilevsky et al., 2019) and thus evaluate if the RMDSs formed during the time of the basaltic plains infill or later.

\subsection{Age Estimation from a Topographic Diffusion Model}

Another method that can be used to constrain the age of a lunar crater is to determine its degradation state by using a topographic diffusion model. Fassett and Thomson (2014) determined the degradation state of about 13,000 lunar craters on the lunar maria, implicitly assuming that the diffusivity was independent of crater size.

Linking their measurements of the degradation states to surface ages, they derived a relationship between degradation state and crater age. More recent work, however, showed that diffusivity varies with crater diameter (Fassett et al., 2018; Xie et al., 2017). Considering this updated crater size-dependent topographic degradation of lunar craters, Fassett et al. (2018) revised the relation of Fassett and Thomson (2014) as:

$$
K_{1000 m}(t)=363.58 t^{5}-2954 t^{4}+8953 t^{3}-13814 t^{2}+16695 t
$$

where $K_{1000 \mathrm{~m}}$ is the diffusion age of a crater with a diameter of $1000 \mathrm{~m}$ which is defined as the product of diffusivity and time (Fassett $\&$ Thomson, 2014), and $t$ is time in Ga. The model of Xie et al. (2017) gives the relation between $K_{1000 \mathrm{~m}}$ and the diffusion age of a crater with an original diameter of $D_{0}$ : 


$$
K_{1000 m}=\left(\frac{1000}{D_{0}}\right)^{0.93} K\left(D_{0}\right)
$$

To determine the diffusion age of each RMDS-superposed crater, we used the approach of Fassett and Thomson (2014) as follows: first, the profile of a

RMDS-embayed crater was derived from a detrended DTM (which is the difference from the DTM to the pre-impact surface). The pre-impact surface is constructed by fitting a plane to the elevation data beyond 1.5 radii from the crater center. The regions used for the extraction of topography are shown as blue polygons in

Supplementary Figure S1. Second, a database of crater profiles in various degradation states was derived from the topographic diffusion model for $D=50 \mathrm{~m}$ to $400 \mathrm{~m}$ craters using the initial crater profile model of Xie et al. (2017). Finally, we found the profile from the database that best matches the profile of each RMDS-embayed crater derived in the first step. The best-fitting profile provides estimates of the original diameter $\left(D_{0}\right)$ and the diffusion age $\left(K\left(D_{0}\right)\right)$ of an observed crater. By using Equation (2), we derived $K_{1000 \mathrm{~m}}$ from the $K\left(D_{0}\right)$, and then by solving Equation (1) we obtained the estimated age of the crater.

\subsection{Age Estimation from Using a Locally Calibrated Monte Carlo Model}

The diffusion rates taken from the literature and used in the previous sections (see Section 4.2) to estimate the ages of the small impact craters overlapped by RMDSs were all derived from global considerations. Furthermore, a general expression for the dependence of the diffusion rate $\kappa$ on the crater diameter $D$ has not been established yet. Hence, we assumed a dependence in the form of a power law 
$403 \kappa=b D^{a}$ (Fassett et al., 2018) and determined the parameters $a$ and $b$ based on the 404 cumulative size-frequency distribution (CSFD) of an area located close to the 405 RMDS-overlapped crater. The Monte-Carlo cratering model introduced by 406 Bugiolacchi and Wöhler (2020) was then adapted to the observed CSFD, thus 407 yielding the parameters $a$ and $b$ for the region under study. In turn, these locally 408 calibrated parameters allow for an estimation of the ages of craters overlapped by 409 RMDSs.

410 For counting the craters, we build upon the deep-learning-based automatic 411 detection algorithm introduced by Wilhelm and Wöhler (2021). The original method 412 relies on a convolutional neural network (CNN) that is applied to windows of variable 413 size extracted from an LROC NAC image. In this study, however, to achieve 414 robustness concerning variable illumination conditions, we trained the $\mathrm{CNN}$ to 415 high-resolution LROC NAC DEM data obtained by shape from shading (Grumpe \& 416 Wöhler, 2014; Grumpe et al., 2016; Zhang et al., 2020). The training data for the 417 CNN were extracted from the DEM using the manual crater annotations by Fisher 418 (2014), consisting of a set of 852 crater locations with diameters between 5 and $41 \mathrm{~m}$, 419 determined based on a LROC NAC image. The LROC NAC DEMs presented by 420 Zhang et al. (2020) have a pixel size of $2 \mathrm{~m}$. As the technique of Wilhelm and Wöhler 421 (2021) is specifically favorable for detecting small craters of about 5-10 pixels size, 422 the LROC NAC DEM under study was presented to the CNN in 23 down-sampled 423 resolution levels covering a factor of 12 , so that all craters between 10 and $100 \mathrm{~m}$ 
424 diameter were detected with virtually the same probability. Since most craters are

425 detected several times on different resolution levels with slightly different estimated

426 center positions and/or diameters, a clustering stage is used to aggregate multiple

427 detections of the same crater. For further details about the algorithm see Wilhelm and

428 Wöhler (2021). The automatic crater counts were then used to construct the CSFD of

429 the examined region in the crater diameter interval of $10-100 \mathrm{~m}$.

430 To obtain parameters $a$ and $b$, we used the Monte-Carlo cratering model of

431 Bugiolacchi and Wöhler (2020). This model simulates the population of small craters

432 with diameters between 10 and 100 m over time by adopting the cratering rate and

433 production function of Neukum et al. (2001), where the number of craters per

434 diameter interval is modeled by a Poisson distribution whose mean is defined by the

435 production function. Given the values of $a$ and $b$, a diffusion rate and thus a lifetime

436 can be assigned to each crater according to its diameter. Based on Fassett et al. (2014)

437 it is straightforward to show that the crater lifetime $T_{\text {life }}$ is given by

$$
T_{\text {life }}=\frac{T_{\text {life }}^{(0)} \kappa_{0}}{D_{0}^{2} b} D^{2-a}
$$

439 with $T_{\text {life }}^{(0)}$ as the lifetime of a crater with diameter $D_{0}$ for a diffusion rate $\kappa_{0}$, where

$440 \quad D_{0}$ and $D$ are given in $\mathrm{km}$. Assuming that the lifetime of a crater is reached once its

441 depth has fallen below $1 \%$ of its initial diameter, we found by numerical integration of

442 the standard diffusion equation (e.g., Fassett \& Thomson, 2014) that for a crater with

$443 D_{0}=0.3 \mathrm{~km}$ and $\kappa_{0}=7 \mathrm{~m}^{2} / \mathrm{Ma}$ it is $T_{\text {life }}^{(0)}=3.07 \mathrm{Ga}$, assuming the initial

444 cross-sectional crater profile proposed by Fassett et al. (2014). The factor $\frac{T_{\text {life }}^{(0)} \kappa_{0}}{D_{0}^{2}}$ in 
445

446

447

equation (3) is a dimensionless normalization constant whose value is 0.239 , independent of the chosen values of $\kappa_{0}$ and $D_{0}$. The diffusion equation determines that the value of $T_{\text {life }}^{(0)}$ is proportional to $D_{0}^{2}$ and to $1 / \kappa_{0}$, so that the value of the normalization constant does not change upon variations of $\kappa_{0}$ and $D_{0}$.

At each time step of the simulation, it is checked for each crater if its age exceeds its lifetime; if this is the case, the crater is marked as invisible. Other mechanisms to make a crater disappear are destruction by a new larger crater and covering of the crater by the ejecta of a new larger crater. In our simulations, we found that these mechanisms are 2-3 orders of magnitude less efficient than diffusion for the diffusion rates inferred for our three regions under study (see Table 1). Our model also takes into account the gradual increase of the crater diameter over time (Bugiolacchi \& Wöhler, 2020; Xie et al., 2017). At any desired time step, a CSFD can be extracted from the simulated crater population. For the crater diameter interval of 10-100 m, we found for any reasonable choice of $a$ and $b$ that yields values for the diffusion rate comparable to the literature (e.g., Fassett et al., 2014) that the CSFD converges into an equilibrium state after at most $100 \mathrm{Ma}$.

Because of the Monte Carlo nature of our model, the simulated CSFD at a specific moment in time is different for each simulation run. It is thus not possible to fit the cratering model to the observed CSFD with standard, e.g., gradient-based, optimization techniques due to the statistical fluctuations of the error function. Hence, we perform the fitting of the model parameters using a Bayesian optimization 
466 technique (e.g., Gelman et al., 2013; Snoek et al., 2012), which is able to cope with a

467 non-deterministic error function. We chose the sum-of-squares deviation between the

468 measured and modeled logarithmic CSFD values as the error function and optimized

469 the logarithms of two diffusion rates $\kappa_{10}$ and $\kappa_{100}$ for craters of $0.01 \mathrm{~km}$ and $0.1 \mathrm{~km}$

470 diameter, respectively, which are related to the parameters $a$ and $b$ by $a=$

$471 \log _{10}\left(\kappa_{100} / \kappa_{10}\right)$ and $b=10^{a+\log _{10} \kappa_{100}}$. The obtained values of $\kappa_{10}$ and $\kappa_{100}$ are

472 listed in Table 1. For all three examined regions located close to the

473 RMDS-overlapped craters shown in Figures 2a-2c, respectively, the smallest 2-3

474 diameter intervals are excluded from the fit because they are already influenced by the

475 rollover effect, i.e., an artificial flattening of the CSFD due to incomplete detection of

476 the smallest craters.

477 Apart from computing the lifetime of the RMDS-overlapped craters, the values

478 of $a$ and $b$ found by the Bayesian optimization routine also allow for estimating the

479 actual age of these craters, given their diameters and depths. These dimensions

480 correspond to $0.3 \mathrm{~km} / 15 \mathrm{~m}$ for the RMDS-overlapped crater-containing areas

481 (Figures 2a and 2c) and $0.13 \mathrm{~km} / 4 \mathrm{~m}$ for the area close to the case shown in Figure

482 2b. Using the initial cross-sectional crater profile of Fassett and Thomson (2014) and

483 a diffusion rate of $\kappa_{0}=7 \mathrm{~m}^{2} / \mathrm{Ma}$, we found that a crater of diameter $D_{0}=0.3 \mathrm{~km}$

484 needs a time of $T^{(0)}=630 \mathrm{Ma}$ and $1040 \mathrm{Ma}$, respectively, until it reaches these

485 depth/diameter ratios. Since the time needed by a crater to reach a certain degradation

486 state is proportional to the squared diameter $D^{2}$ and inversely proportional to the 
diffusion rate $\kappa$, the crater age $T$ is then given by:

$$
T=\frac{T^{(0)} \kappa_{0}}{D_{0}^{2} b} D^{2-a}
$$

\section{Results}

\subsection{RMDS-Impact Crater Embayment Relations}

The RMDS-crater-overlap examples (red stars, Figure 1; see also other candidate cases in Supplementary Figure S2) were identified from spectrally defined mare units older than 2.0 billion years based on crater size-frequency distribution (CSFD) measurements (Hiesinger et al., 2006; 2011). The features in Figures 2a-2d are in Maria Tranquillitatis, Humorum, Fecunditatis, and Tranquillitatis, respectively, corresponding to the mare units T26 (3.46 Ga), H6 (3.46/3.75 Ga), F7 (3.34/3.62 Ga), and T18 (3.62 Ga) defined by Hiesinger et al. (2006, 2011). The two cases in Figures 2e and $2 \mathrm{f}$ are in Imbrium mare unit I30 (2.01 Ga). Clearly, if RMDSs had formed concurrently with the emplacement of these mare lava flows, they would have ages comparable to those of their hosting mare units, i.e., $>2.0 \mathrm{Ga}$ (Supplementary Figure S3). Therefore, these embayment relationships alone would contradict the hypothesis of synchronous formation of the mare basalt host unit and the associated RMDSs (Wilson et al., 2019; Zhang et al, 2017, 2020; see Section 3 for more details).

\subsection{Degradation Ages of Impact Craters Embayed by RMDSs}

Morphologic and morphometric characteristics suggest Copernican-aged $(<1000$ Ma) basaltic mare volcanism associated with RMDSs. Figure 2 presents six cases when RMDSs appear to be superposed on adjacent craters. A three-dimensional rendering based on NAC-derived DTMs is shown in Figure 3. NAC DTM-based 
511 topographic profiles extracted along the lines cutting across these craters and the

512 RMDSs can be found in our supplementary Figures S4-S9. The statistical results

513 obtained according to the topographic information are listed in Table 2. The D and d

514 of both craters superposed by RMDSs in Figures $2 \mathrm{a}$ and $2 \mathrm{c}$ are $\sim 300 \mathrm{~m}$ and $\sim 15 \mathrm{~m}$

515 respectively, resulting in a d/D $\sim 0.05$ with a maximum steepness of the inner slope, $\alpha$,

516 of $\sim 9^{\circ}$. This type of crater belongs to the morphologic class $\mathrm{C}$ defined by Basilevsky

517 (1976), corresponding to an age between 750 and $1500 \mathrm{Ma}$ (Figure 4 and Table 2).

518 The crater in Figure $2 b$ is $\sim 130 \mathrm{~m}$ in diameter with a shallow depth of $4 \mathrm{~m}, \mathrm{~d} / \mathrm{D}$

519 of 0.031 and $\alpha$ about $6-8^{\circ}$. Its estimated age appears to be in the range of $\sim 160-320$

520 Ma. Figure 2d shows a RMDS of a size of $140 \times 160 \mathrm{~m}$ and a height of 1-1.5 m,

521 overlapping a $140 \mathrm{~m}$ crater. This RMDS-superposed crater has $\mathrm{d} \sim 7-9 \mathrm{~m}, \mathrm{~d} / \mathrm{D}=$

$5220.04-0.06$, and a maximum inner slope angle of $8-9^{\circ}$. It is classified as a type $\mathrm{C}$ crater

523 in its intermediate phase of destruction (Basilevsky, 1976), thus giving an age of

524 around 200-300 Ma and, consequently, requiring an even younger age for the

525 superposed RMDS. Therefore, the RMDSs that superposed these craters should be

526 younger than these age values, thence, the crater ages provide a maximum age for the

527 RMDS emplacement events.

528 The RMDS in Figure $2 \mathrm{e}$ is $2-3 \mathrm{~m}$ tall, $\sim 170 \mathrm{~m}$ across and superposed on a crater

529 with $\mathrm{D} \sim 100 \mathrm{~m}$. Its slopes are $2-3^{\circ}$ to $8-10^{\circ}$ (at the contact with the crater). The

530 embayed crater has a depth (d) of 5-6 m with a range of d/D values of $0.05-0.06$, and

531 its inner slopes are up to $8-10^{\circ}$ steep. Morphologically, it belongs to the crater of class 
532 C (Basilevsky, 1976; Figure 4) in the first half of its life, corresponding to an age of 533 200-300 Ma.

534 The RMDS in Figure $2 \mathrm{f}$ is characterized by an elliptical shape in plain view, with

535 a dimension of $230 \times 280 \mathrm{~m}$, and the diameter $\mathrm{D}$ of the crater superposed by the

536 RMDS is $\sim 135 \mathrm{~m}$. The RMDS is only $\sim 2 \mathrm{~m}$ high and its slopes just up to $3-4^{\circ}$ steep.

537 The depth of the crater is $\sim 5-7 \mathrm{~m}$, and so the ratio $\mathrm{d} / \mathrm{D}>0.04$. The maximum inner

538 slope angle of the crater is $\sim 7-8^{\circ}$. It belongs to craters of class $\mathrm{C}$ and its age is

$539 \sim 200-300 \mathrm{Ma}$ (Figure 4 and Table 2), and thus, the age of the embaying RMDS should

540 be $<200-300$ Ma.

541

542

5.3 Diffusion Model Ages for Impact Craters Embayed by RMDSs

Based on a topographic diffusion model (Fassett \& Thomson, 2014; Xie et al.,

544 2017), degradation states for the six craters of different sizes which are embayed by

545 RMDSs to varying degrees, were derived using $\sim 2 \mathrm{~m} /$ pixel NAC DTMs. Their crater

546 topography (Supplementary Figure S10) and model fits results are shown in Figure 5

547 and Table 2. The ages of RMDS-embayed craters range from 130 to $1000 \mathrm{Ma}$. There

548 is a positive correlation between the ages and diameters of these craters superposed by

549 RMDSs, possibly because smaller craters preferentially sample younger ages, as the

550 lifetime of craters increases with size (Xie et al., 2017). These findings provide

551 additional support for a younger age of RMDS emplacement (Figure 4), uncoupled

552 from the surrounding mare infill events.

5535.4 Simulation Results from Using a Locally Calibrated Monte Carlo Model

554 Simulation results for the RMDS-impact crater embayment areas (Figures 2a-2c) 
555 obtained with the median values of $\kappa_{10}$ and $\kappa_{100}$ are shown in comparison with the

556 observed CSFDs in Figure 6. The distributions of the resulting lifetimes and ages of

557 the RMDS-overlapped craters in the three areas (i.e., areas located close to the

558 RMDS-overlapped craters in Figures 2a-2c, respectively) are shown as boxplots in

559 Figure 7. The inferred median ages of the RMDS-overlapped craters are all younger

560 than $200 \mathrm{Ma}$, and the upper marginal values of the distributions are below $500 \mathrm{Ma}$.

561 These crater age values are upper limits to the ages of the overlapping RMDSs, again

562 providing additional evidence for favoring the young age (i.e., Copernican in age,

$563<1.1 \mathrm{Ga}$ ) of RMDS-formation-related mare volcanism.

564

565

566

567

568

569

570 could help to resolve the age conundrum for the formation of RMDSs.

573

574

575

576

577

\section{Discussion}

The detailed hypothesis for RMDS formation concurrent with the host lava flow (e.g., Wilson et al., 2019) has been described in Section 3. We now outline in more detail: 1) the list of observations that conflict with the prediction of the concurrent RMDS-host lava flow formation; and 2) a set of observations that any hypothesis for the young origin of RMDSs relative to their host basalt unit must address. We conclude with a set of research and human/robotic mission goals and objectives that

\subsection{Contradictions to Predictions of the Contemporaneous Host-Lava Flow-RMDS Formation Model}

Several observations contradict the predictions of the Wilson et al. (2019) model of the contemporaneous formation of the host lava flows and RMDSs. Examination of 
578 the relation between RMDSs (diameters in the range of hundreds of meters) and

579 impact craters of about the same size and smaller shows that numerous case studies

580 selected from a large population pool of more than 8,000 RMDSs (Figure 1; Zhang et

581 al. 2020) support the occurrence of eruptive volcanism on the Moon much younger

582 than proposed by the model. Additionally, as estimated by Fassett and Thomson (2014)

583 and others, the smaller-than-300 m crater retention ages for the Moon are consistent

584 with ages substantially younger than $3.0 \mathrm{Ga}$. Furthermore, according to the current

585 understanding of small lunar crater degradation rates based on diffusivity models (e.g.,

586 Fassett \& Thomson, 2014; Xie et al., 2017), some craters embayed by RMDSs are so

587 small (even less than $\sim 150 \mathrm{~m}$ diameter, Figure 2 and Supplementary Figure S2 for

588 other candidate examples) that they could not have survived for $3 \mathrm{Ga}$. Based on the

589 NAC-derived digital terrain models (DTMs, Grumpe \& Wöhler, 2014; Grumpe et al.,

590 2016), the model ages of RMDS-superposed small craters can be inferred from

591 topographic measurements (Basilevsky, 1976) and a topographical diffusion model

592 (Xie et al., 2017). However, given the widespread distribution of the RMDSs across

593 lunar mare surfaces, these potential younger ages have implications that would

594 revolutionize our models of the thermal history of the Moon (Shearer et al., 2006). We

595 also explored morphologically similar endogenetic crater features occurring in

596 terrestrial basaltic lava flow fields and cannot rule these out, but even if the features

597 embayed were not typical impact craters, the required billions of years lifetime of

598 such small depressions appear unlikely. We now turn to several lines of evidence and 
599

600

601

602

603

604

605

606

607

608

613

614

615

616

617

additional related factors, and address them individually.

\subsubsection{RMDS-Impact Crater Embayment Relations}

Could the examples of identified RMDS-embayed craters (e.g., Basilevsky et al., 2019; Figures 2 and 3) have formed during host lava flow emplacement (for example, after the emplacement of the flow but before its final inflation, cooling, second boiling, volatile release and RMDS eruption)? Wilson et al. (2019) estimate that the duration of flow emplacement and solidification is of the order of less than several years, and thus it is: 1) highly improbable that an individual superposed impact crater would form during this extremely short period (even in a period of relatively higher flux; Stöffler et al., 2006); and 2) also highly improbable that such an impact crater would survive over three billion years of subsequent regolith development. Could the RMDS-embayed craters be contemporaneous with flow emplacement and be of endogenetic origin? Inflation features in terrestrial basaltic lava flow fields provide clues as to the mode of formation of crater-like depressions. Some endogenetic surface depressions represent circular lava-rise (or inflation) pits (Figure 8) formed by the vertical inflation of the host lava flow around local topographic highs on the pre-flow surface, leaving a depression (e.g., Hamilton et al., 2020;

Walker, 1991). In other cases on Earth, lava mounds, all high areas within a lava field, are sometimes locations for the formation of small drained sub-lava-crustal lava caves (Grimes, 2002), whatever the process of mound formation.

In addition, in the RMDS contemporaneous formation model, the RMDSs could 
621 collapse due to the removal of the pressure or withdrawal of melt that caused their

622 eruption. An array of circular to irregular-shaped collapses or depressions associated

623 with RMDSs has been observed during our investigations (Zhang et al., 2017, 2020).

624 This could also be comparable to a range of variation among tumuli displaying

625 summit cracks and various types of collapse (e.g., Ollier, 1964; Walker, 1991).

626 Terrestrial basaltic lava flow fields emplaced by inflation commonly display

627 depressions of variable shapes. For example, the Aden flows, located in south-central

628 New Mexico, covering an area of $\sim 75 \mathrm{~km}^{2}$ consist of thin vesicular flows (De Hon \&

629 Earl, 2018; Hoffer, 1976). The Aden inflated flows are pock-marked with inflation

630 pits 20 to $150 \mathrm{~m}$ across and 4 to $5 \mathrm{~m}$ deep (Figure 8). They are characterized by gentle

631 interior slopes caused by the continuous extensional collapse of the marginal crust. In

632 some areas, molten rock withdrew from subterranean spaces (such as drained lava

633 tubes), leaving voids into which the surface collapsed, forming a series of collapse

634 pits/depressions.

635 On Earth, dimple-shaped drainage craters (Greeley, 1970) and raised-rim

636 collapse craters (Greeley \& Gault, 1979) were found in basaltic lava flows and

637 interpreted as endogenic morphologies formed in association with lava tubes.

638 However, previous studies (e.g., Greeley \& Gault, 1979) often misinterpreted

639 lava-rise or inflation pits (Walker, 1991) as collapse depressions. Impact crater-like

640 profiles are expressed through several inflation pits (e.g., Figure 8). Nevertheless,

641 whether their formation was related to lava tubes or not, collapsed craters should also 
642 exist on the Moon and other planetary surfaces where basaltic volcanism has once

643 occurred and have an appearance practically indistinguishable from small impact

644 craters (e.g., $100 \mathrm{~m}$ or smaller). Collapse crater size is mostly governed by the lava

645 flow thickness (e.g., Greeley \& Gault, 1979) and subsurface tube dimensions. Lunar

646 basaltic lavas are more fluid than the terrestrial equivalent (Williams et al., 2000), and

647 more collapse craters tend to form in these, relative to more viscous flows (Greeley \&

648 Gault, 1971).

649 Terrestrial inflation and collapse pits appear to be most frequent on inflation

650 plateaus, whereas circular mound-like positive features are also found to coexist with

651 these negative features. An inflation plateau (Figure 8) represents a topographically

652 flat-topped uplift resulting from a kind of uniform "inflation" by injection of lava

653 beneath a rigid upper crust (Hon et al., 1994; Walker, 1991; Wentworth \& Macdonald,

654 1953). During the repeated inflation process (Self et al., 1998; Wilson et al., 2019),

655 interior hot lava can reach the surface via cracks in the flexing lava crust which

656 formed when the interior pressure exceeds the tensile strength of the overlying cooled

657 flow layer. Crater-like forms and circular tumulus-like structures (yellow and white

658 arrows in Figure 9) on inflation plateaus in the Amboy lava flow field, Mojave Desert,

659 California, reveal various inflation-caused positive and negative features formed

660 during flow emplacement. Some tumulus-like structures show degraded appearances

661 to varying degrees (red arrows, Figure 9). Among these, one shows a central collapse

662 pit filled with sand/dust deposits (the upper red arrow, Figure 9), while the lower one 
663 has evolved into a circular collapse depression with a broken, blocky rim (the lower

664 red arrow, Figure 9). These circular negative and positive features on the inflationary

665 lava flow surface provide potentially good analogs for RMDS and crater formation

666 that are very likely to have occurred in basaltic lava flows on the Moon. A better

667 description of the nature of such negative and positive features, both of which are

668 endogenic in origin, is of geologic importance for the full understanding of

669 inflationary features that might have occurred on the Moon, and that might have

670 produced essentially simultaneous circular endogenetic surface depressions into

671 which near-contemporaneous RMDSs might have flowed. Thus, simultaneous

672 endogenetic depressions cannot be ruled out as a candidate to explain the

673 RMDSs-superposed crater-depression embayment relationships (e.g., Figures 2-3 and

674 Supplementary Figure S2).

675 In addition, the RMDS-superposed depressions have impact crater-like raised

676 rims, similar to those of terrestrial collapsed tumuli with broken and blocky raised

677 rims (De Hon \& Earl, 2018; Ollier, 1964). This also allows the possibility that

678 RMDS-superposed craters might be of non-impact origin. Lunar craters that are

679 partially superposed by RMDSs have more gentle interior slopes (commonly $<10^{\circ}$,

680 Section 5.2). The Aden basalt is very young (middle to late Quaternary) with a

681 surface-exposure age of only about 0.2 Ma (Anthony \& Poths, 1992); thus, the

682 comparison with the RMDSs-laden flows of hundreds of millions or even billion

683 years ago on the Moon cannot be straightforward. There should be a strong negative 
684

685

686

687

688

689

690 691 the following section.

700

701

702

703 that needs more research.

correlation between the crater interior slopes and their longevity due to the formation and dynamics of lunar regolith and the fact that lunar topography evolves with time (e.g., Basilevsky, 1976; Fassett et al., 2014). However, if this assumption (i.e., these RMDS-embaying craters were of collapse in origin) is proven to be correct, then the question remains as to how such small craters could have survived billions of years of regolith development on the Moon if the RMDSs had formed concurrently with their host maria (Zhang et al., 2017, 2020; Wilson et al., 2019). We address this question in

Could the RMDS-embayed craters be some sort of post-RMDS impact event, with land sliding and mass wasting then occurring to produce an apparent embayment relationship? For example, could the RMDS-overlapped craters (Figure 2) have formed after the RMDSs? In this scenario, the crater formation event might have triggered landslides of RMDS materials into the craters, creating an apparent embayment relationship, thus weakening the hypothesis of a late-stage formation of the RMDS. However, the very gentle slopes (a few degrees only) typical of the RMDSs are probably not steep enough to trigger landsliding. Nonetheless, an improved understanding of how post-impact-crater formation mass wasting could modify and shape the RMDS-associated morphologies is necessary to fully address this relationship. Mass wasting and the possible role it played in shaping RMDS-hosting lava flow morphology in inflated mare regions is an important topic 
707 and Supplementary Figure S2), and, consequently, to have formed later. Based on

708 flow cooling and solidification time, such depressions are unlikely to be of impact

709 origin that occurred simultaneously with flow emplacement. Endogenetic craters that

710 form simultaneously with the host lava flow are well-known in terrestrial lava flow

711 fields and cannot be ruled out as a contributing factor to these RMDS-crater

712 embayment examples. Taken together, however, these crater embayment relationships

713 strongly suggest that RMDS formation did not occur simultaneously with host lava

714 flow emplacement, thus apparently invalidating the hypothesis (Wilson et al., 2019)

715 of flow inflation and second boiling for contemporaneous emplacement of the host

716 lava flow and extruded RMDSs. Having assessed the relative ages of these

717 RMDS-embayed crater examples, we now turn to an analysis of the morphology and

718 morphometry of the embayed craters to assess their absolute ages and to estimate the

719 amount of time between host lava flow emplacement and emplacement of the

720 superposed RMDSs.

\subsubsection{Degradation Age of Impact Craters Embayed by RMDSs from} Morphometric Analysis

A summary of the crater-degradation age dating results (see Section 5.2) and their implications for the maximum ages of the superposed RMDSs that embay them origin and to have undergone typical degradation rates since their formation 
728 (Basilevsky, 1976), have maximum ages of hundreds of millions of years. Thus they

729 are likely to have formed in the Copernican Period, significantly post-dating the

730 formation of the mare basalt host units, and raising questions on the hypothesis for the

731 simultaneous formation of RMDSs and their host mare basalt unit (e.g., Wilson et al., 732 2019).

733

734

735

\subsubsection{Lateral Diffusion and Erasure of Small-Scale Topography: Age Estimation from Topographic Diffusion Models}

2017), the degradation states for the six craters of different sizes (Figures $2 \mathrm{a}-2 \mathrm{f}$ )

which are embayed by RMDSs to varying degrees, were derived using $\sim 2 \mathrm{~m} /$ pixel

NAC DTMs. Their crater topography (Supplementary Figures S4-S9) and model fit

results are shown in Figure 5 and Table 2. The ages of RMDS-embayed craters range

744 (Xiao \& Werner, 2015). Some craters overlapped by RMDSs are so small (even less

745 than $\sim 150$ m diameter, Figures $2 \mathrm{e}$ and $2 \mathrm{f}$ ) that they cannot have retained their

746 morphologies for up to $3 \mathrm{Ga}$, the young age of the majority (peak temporal occurrence)

747 of the maria (Hiesinger et al., 2011) in which the RMDSs are found. The crater

748 degradation models predicted that the maximum lifetime of a $\mathrm{D}=150 \mathrm{~m}$ lunar crater

749 was $\sim 800 \mathrm{Ma}$ (Fassett \&Thomson, 2014). These results provide additional support for

750 a younger age of less than $1.0 \mathrm{Ga}$ for these RMDSs. 
751

752

753

754

755

756

757

758

759

760

761

762

763

764

765

766

767

768

769

770

771

772

773

\subsubsection{Age of Impact Craters Embayed by RMDSs from a Locally Calibrated} Monte Carlo Model

The diffusion rates used in Section 6.1.3 to estimate the ages of the small impact craters overlapped by RMDSs were derived from global considerations. The

Monte-Carlo cratering model introduced by Bugiolacchi and Wöhler (2020) treats the age estimation of craters overlapped by RMDSs locally. The modeling results for the RMDS-impact crater embayment areas (Figures 2a-2c) show that the inferred median ages of the RMDS-overlapped craters are all younger than 200 Ma and the upper marginal values of the distributions are below $500 \mathrm{Ma}$ (Figure 7). These crater age values are upper limits to those of the overlapping RMDSs, given further support to the young age of the RMDS emplacement hypothesis.

\subsubsection{Age of RMDSs Inferred from Regolith Thickness Development Models}

In addressing the problem of the formation age of RMDSs, it is worth considering the effect of regolith-forming impact gardening, which influences the entire exposed lunar surface (McKay et al., 1991). Despite their modest height ( 3.5 m on average for the measured 532 RMDSs; Zhang et al., 2020) and gentleness of their slopes (summit slope $<5^{\circ}$ and marginal slope up to $10^{\circ}$, Zhang et al., 2020), RMDSs in images with relatively low sun-illumination angle look distinct, with well-defined outlines.

A key observation is that RMDSs do not show a sequence of morphologic degradation, as do craters formed on mare surfaces over a long time. Instead, individual RMDSs, RMDS chains, and RMDS clusters formed on host basaltic units 
774 of a variety of ages (Hiesinger et al., 2011) are characterized by comparable

775 morphologic sharpness and crispness. For example, nearly all the RMDSs highlighted

776 in this study are located within mare lava plains with absolute model ages of 3.2-3.6

777 Ga, estimated by the spatial densities and size-frequency distributions of superposed

778 craters (e.g., Hiesinger et al., 2011; Morota et al., 2011). How can RMDSs formed

779 simultaneously with their ancient host units retain this comparable crispness if the

780 original units are of different ages and if superposed craters, comparable in scale to

781 RMDSs, are undergoing constant micrometeorite bombardment, degradation, and

782 destruction?

783 Regolith is created by impact gardening of the lunar surface (Shoemaker et al.,

784 1969) and its mean thickness in maria is estimated to be about 4-5 m (e.g., Bart et al.,

785 2011; Basilevsky, 1974; McKay et al., 1991; Shkuratov \& Bondarenko, 2001). The

786 process of regolith formation encompasses two interrelated issues: 1) craters are

787 excavated at the impact point by penetration through the regolith into underlying

788 basaltic regolith protolith (e.g., Head \& Wilson, 2020), resulting in an increase in the

789 thickness of the regolith in any given region; 2) ejecta from these craters form

790 regolith-like material, which is thicker closer to the crater and progressively thinner

791 with distance. Although a minimal part of the ejecta is ballistically transported to great

792 distances (kilometers and tens of kilometers), a significant part of the ejecta is

793 deposited near the point of impact from a few tens to a few hundred meters depending

794 on the size and velocity of the impactor. This scenario was supported by observations 
795 of the thinning of the regolith layer in the rim crest region of relatively large linear 796 depressions (Rima Hadley - Apollo 15; Fossa Recta - Lunokhod 2) where ejecta from 797 small craters are scattered in all directions but the adjacent depression is effectively a 798 zone of negative balance of ejected material (Basilevsky et al., 1977; Swann et al., 799 1972).

800 The lunar maria with an average age of $\sim 3.5 \mathrm{Ga}$ (Hiesinger et al., 2011) have 801 since been reworked to a depth of 4-5 m, thus destroying pre-existing features of this 802 height (as most of RMSDs are). Larger features had their topographic relief reduced 803 and were smoothed with a loss of morphological sharpness. RMDSs could have 804 developed their present characteristics in the last $1 \mathrm{Ga}$ only if the cumulative cratering 805 flux had been an order of magnitude smaller in the last $3.5 \mathrm{Ga}$ (e.g., Hartmann et al., 806 2007, their Figure 4). The ejecta excavated from small craters close to the areas 807 surrounding any RMDS would have had a strong influence on the original 808 morphology of RMDSs. Thus, these relationships and factors seem to require that 809 RMDSs should have been very significantly modified or even destroyed if they had

810 formed coincident with peak mare volcanic activity $~ 3.0-3.7$ Ga ago. Regolith

811 development principles would predict that RMDS marginal steep slopes and

812 surrounding ring moats would be locations most sensitive to this type of destruction.

813 Given that many RMDSs, including the cases reported in this study, share a

814 well-preserved morphology (Zhang et al., 2020), we are led to conclude based on 815 regolith development models that any RMDS formed on host-mare basalt units in 
816 these ancient times would have been degraded and obliterated in the ensuing period of

817 regolith development: consequently, the RMDSs seen in association with these

818 ancient host units were not formed synchronously with these units but must, instead,

819 be relatively young, of Copernican age (from $\sim 1100$ Ma to present).

820

821

\subsubsection{Density Distribution of Superposed Impact Craters}

The size-frequency distributions of superposed impact craters on the

823 RMDS-hosting mare units have been used to estimate the Absolute Model Ages

824 (AMAs) of these units (e.g., Hiesinger et al., 2011) and these hosting units are

825 predominantly more than $\sim 3 \mathrm{Ga}$ in age, as described above. However, if the evidence

826 points to a much younger age for the specific examples that embay degraded craters,

827 and regolith and diffusional degradation modelling favor a Copernican age for all

828 RMDSs, what then are the AMAs of the RMDSs themselves?

829 Unfortunately, individual RMDSs are too small (average diameter $\sim 200 \mathrm{~m}$ ) to be

830 dated reliably (e.g., van der Bogert et al., 2015). One approach would be to count

831 superposed craters on RMDSs occurring in large clusters to build up sufficiently

832 robust statistics to make the counts reliable, but such analyses have not yet been

833 undertaken.

834 If RMDSs represented a specific facies of lunar mare basaltic volcanism it would

835 be logical to expect that they formed between 3.9 to $3.3 \mathrm{Ga}$ (e.g., Head \& Wilson,

836 2017); this agrees with estimates (Zhang et al., 2017) from counts of craters $\geq 300 \mathrm{~m}$

837 on a $60 \mathrm{~km}^{2}$ area containing both RMDSs and adjacent mare surfaces. The absolute 
838

model age (AMA) of this "mixture" was estimated to be $3.2+0.2 /-0.7 \mathrm{Ga}$, although this figure was based on counts of only 12 craters. Therefore, counts of smaller craters were also involved (Zhang et al., 2017): producing AMAs of $25 \pm 2 \mathrm{Ma}$ for the RMDSs and $36 \pm 0.5 \mathrm{Ma}$ for the adjacent mare. However, using small, sub-km diameter impact craters to date very young planetary surfaces is not a scientifically robust methodology, given that their lifespan and distribution are more susceptible to varying degrees of degradation over geological times (Williams et al., 2018).

Consequently, the distribution of craters smaller than 300-500 m can be assumed to be in equilibrium, i.e., the crater size-frequency distribution (CSFD) is less steep (slope approximately -2) and lies well below the CSFD predicted by the "de-facto standard" Neukum et al. (2001) model (see, e.g., the CSFD of the planned Chandrayaan-2 landing site shown by Sinha et al., 2020; see also Xiao and Werner, 2015).

Nonetheless, the difference was explained by Zhang et al. (2017) as being due to "several physical factors related to the target's properties, such as porosity, the thickness of the regolith, the angle of slope, etc., affecting the rate of degradation". The major question, however, remains the alleged very young age. One possibility considered was that they represent "geologically very recent small eruptions occurring several billion years after the emplacement of the mare lava flows" (Zhang et al., 2020). A second scenario considered was that RMDSs are formed from magmatic foams below a cooling lava flow surface and extruded to produce the domes above the solid basaltic flow top as the flow evolved (Wilson \& Head, 2017b). Impacts into 
861 Michael (2021), impact craters superposed on the analogous mounds in the Ina

862 small-shield pit crater (Qiao et al., 2019) appear similar in morphology to those in the 863 surrounding maria.

\subsubsection{Morphologic Characteristics of Impact Craters Superposed on RMDSs}


881 typical impacts into magmatic foam suggested by Wilson and Head (2017b). The

882 presence of meter-sized boulders on the rim and inside the crater, and the prominently

883 rounded rim crest both suggest its formation in a stratified target, with fragmental

884 material overlying a more coherent rock target.

885 Figure 11 shows a second case, in which three craters are superposed on a 450-m

886 diameter RMDS. Crater 1 is $170 \mathrm{~m}$ in diameter and craters 2 and 3 are each $80 \mathrm{~m}$ in

887 diameter; Basilevsky et al. (2019) focused their analysis on craters 2 and 3.

888 The morphologic class (Figure 11a) of crater 1 is $\mathrm{C}$ (age $\sim 300-600 \mathrm{Ma}$;

889 Basilevsky et al., 2019). The $80-\mathrm{m}$ craters 2 and 3 have prominent rims, $\mathrm{d} / \mathrm{D}=0.08$

890 and 0.05 and $\alpha \sim 12$ and $7 \mathrm{deg}$.; these are interpreted as craters of morphologic class

891 BC transitional to $\mathrm{C}$ (crater 2) and class $\mathrm{C}$ (crater 3). The ages of these craters should

892 be $\sim 100-200 \mathrm{Ma}$ (Basilevsky, 1976) or less than $500 \mathrm{Ma}$ (Fassett \& Thomson, 2014).

893 The RMDS in Figure 11a should therefore be older than a few hundred Ma.

894 Meter-sized boulders are clearly seen on the rim of crater 2 (Figure 11b), suggesting

895 an age of the order of several tens of Ma (Basilevsky et al. 2015). Topographic

896 profiles of the craters (Figure 11c) appear normal, in contrast to those predicted for

897 impacts into magmatic foam (Head \& Ivanov, 2019; Wilson \& Head, 2017b).

898 Baslievsky et al. (2019) interpreted the presence of these meter-sized boulders both on

899 the rim and inside this crater to indicate that the superposed crater formation had

900 occurred in a massive rock target, not in thick magmatic foam.

901 In summary, these examples of superposed craters suggest that the RMDS 
902 mound substrate is not composed of sufficiently large quantities of extremely

903 vesicular magmatic foams to alter the impact energy partitioning and crater shape of

904 superposing impact craters, casting doubt on simple models of a magmatic foam

905 substrate.

906

907

\subsection{The Lack of Inflationary Fracture Features Associated with RMDSs}

908 One significant outstanding question regarding the hypothesis of an inflation

909 origin of RMDSs (Wilson et al., 2019; Zhang et al., 2017, 2020) remains the absence

910 of associated fracture features for RMDSs and their host mare unit, an important

911 indicator for inflation mechanism in terrestrial basaltic flow fields. Lunar mare

912 surfaces are mantled by a regolith layer of varying thickness up to $\sim 10$ meters (Bart et

913 al., 2011, and references therein). The infilling and erasing of fracture/crack features

914 by regolith development over billions of years are likely (Zhang et al., 2020).

915 The magmatic foam model (Wilson \& Head, 2017b, 2018; Wilson et al., 2019)

916 provides an alternative explanation for the absence of fractures associated with

917 RMDSs and their host mare unit, and for the difficulty in discerning impact crater-like

918 inflation pits (always with highly fractured margins in cases on Earth (Figures 8 and 9;

919 e.g., Garry et al., 2012 and Hamilton et al., 2020). When a flow is emplaced, a more

920 coherent and cooler boundary layer develops at the interface with both space and the

921 cold substrate. As the flow continues to be fed at the source, the surface layer

922 undergoes a process of expansion. The cooling magma will start releasing dissolved

923 volatiles due to the crystallization process. Volatiles will concentrate in the residual 
924 magmatic liquid until it reaches saturation, and second boiling begins generating large

925 quantities of small gas bubbles. The consequent volume expansion will cause an uplift

926 of the brittle crust, thereby producing varying-size fractures on the flow surface. If

927 these fractures extend into the lava containing the new gas bubbles, those bubbles are

928 exposed to the vacuum and expand rapidly. The expansion process propagates back

929 down onto the core of the flow expanding the original bubbles and creating new ones

930 as the lava becomes exposed to lower pressure. This forces the foam that is being

931 produced up into the cracks towards the surface of the crust, filling up the cracks as

932 the foam infiltrates the older surface. Finally, the uppermost part of the foam layer

933 reaches the hard vacuum causing the bubbles to burst, releasing gas, and generating a

934 layer of glass fragments. This disintegration process extends down into the spreading

935 foam and this produces a fine-grained fragmental layer with essentially no cohesive

936 strength - a kind of instant regolith (autoregolith; see Head \& Wilson, 2020) - at the

937 top of the foam layer (Wilson \& Head, 2017b; Wilson et al., 2019). It seems unlikely

938 that this fragmental layer will have a surface appearance that reflects the cracks in the

939 underlying original crust of the flow or even cracks in the foam itself as it cools.

940 RMDSs formed in the Copernican period should have thinning regoliths and

941 relatively undegraded morphologies. Thus, some of these types of formational

942 structures could potentially be preserved, depending on the details of models proposed

943 to account for their very young emplacement. Further examination of high-resolution

944 images of RMDSs and their surroundings are required to assess these points as new 
945 hypotheses are developed for young RMDS formation.

946

947

\subsection{Summary of Evidence for the "Young RMDS Emplacement Model"}

Based on the characteristics outlined previously for the population of the RMDS

949 (Zhang et al., 2017, 2020) and the stratigraphic and morphologic relationships

950 documented in the specific preceding sections, we now summarize the implications

951 for the general characteristics of the nature and mode of emplacement of RMDSs and

952 use these to outline requirements for a new model for their emplacement: this differs

953 significantly from the proposed mode of emplacement of RMDSs in connection with

954 the host mare basalts, involving late-stage processes of flow inflation, cooling, second

955 boiling, and extrusion of magmatic foams to the surface to produce the RMDSs (e.g.,

956 Wilson et al., 2019).

957 Stratigraphic superposition and embayment relationships displayed by several

958 RMDSs and circular features on the host mare surface strongly suggest that the

959 embaying RMDSs postdate the circular features. Although the formation of these

960 craters by endogenic processes during lava flow emplacement cannot be confidently

961 ruled out, the most likely origin for the embayed craters is superposed impact events,

962 and this indicates that some unknown period of time elapsed between cooling of the

963 host lava flow, formation of the embayed crater, and then embayment by the RMDS.

964 How much time elapsed between the superposed crater formation and the RMDS

965 embayment? Analysis of the state of degradation of the craters and quantitative

966 models of crater degradation indicate that the embayed craters are on the order of 
several hundred million years old (Figure 5 and Table 2). Although these are maximum ages (the RMDS could have formed and embayed the crater at any time after the formation age of the crater), they nonetheless indicate that the embaying RMDSs formed during the Copernican Period, several billion years later than the host lava flow. What are the absolute ages of these examples in the Copernican period? Unfortunately, these embaying RMDSs are too small to be dated reliably with superposed CSFD methods.

However, two other approaches support a young Copernican age not only for the RMDS-embayed crater examples, but for the whole RMDS population. Current models of diffusion-dominated landform degradation independently indicate that the dome-like structures and the morphologically and topographically distinct moats surrounding RMDSs could not have survived since the time of emplacement of the host lava flows. Secondly, regolith formation models indicate that continuous impact development of regolith in the time since emplacement of the host lava flows would have produced thicknesses up to, and in many cases exceeding, twice the amplitude of the topographic characteristics of RMDSs, and thus would have obliterated them if they had formed concurrently with the host lava flow regolith protolith.

Is there any further evidence to support the ancient origin of the RMDSs and their formation concurrently with the emplacement of their host lava flow? The Wilson et al. (2019) model predicts that the late-stage behavior of cooling lava flows favors extrusion of vesicle-rich foamy lavas onto the surface to produce the RMDS 
988

989

990

991

994

996

1000

1001

1002

1003

1004

1005

mounds, and concurrent subsidence of the lava flow surface to produce the surrounding moats. For some similar types mound of features associated with the Irregular Mare Patch Ina, Qiao et al. (2019) and Wilson and Head (2017b) have suggested that the mounds may be characterized by foamy lavas that have a highly vesicular and possibly aerogel-like structure: consequently, superposed impact craters might be characterized by a different morphology and morphometry. Basilevsky and Michael (2021), however, have presented evidence that impact craters superposed on the Ina floor mounds have morphologies that are comparable to those in the surrounding maria. Remaining uncertain from the model predictions, however, are the ranges of thicknesses of these foam layers, and the effects of the formation of an "autoregolith" by explosive modification of the upper layer of the extruded foams. Both factors need to be modeled to obtain a more specific picture of the original erupted and solidified substrate protolith (Head \& Wilson, 2020) to test with observations of the morphology and morphometry of superposed impact craters formed subsequently.

In summary, these relationships strongly support a young Copernican-era age for the RMDS population, an age that postdates by more than two billion years that of its host lava flows, and thus appear to invalidate the ancient RMDS model of concurrent host-lava flow and RMDS formation (Wilson et al, 2019). However, quantitative measurements of 532 RMDSs in 12 different mare settings reveal some unique distribution patterns for their $\mathrm{h} / \mathrm{D}$ ratios but within a constrained range $1 / 200$ to $6 / 200$ 
1009 with the most common $\mathrm{h} / \mathrm{D}$ ratio being around 4/200, which represents more than $30 \%$

1010 of all RMDSs measured in each basin (Zhang et al., 2020; their Figure 5). The relative

1011 distribution of h/D illustrates that Procellarum and Fecunditatis show comparable

1012 overall distribution shapes peaking again at $0.02(4 / 200)$ but with ratios skewed

1013 toward higher $\mathrm{h} / \mathrm{D}$ values for Tranquillitatis. This means that there are subtle

1014 differences in RMDS morphology, and this would imply a wider time range for the

1015 formation of lunar RMDSs given that there is broad age diversity for the emplacement

1016 of RMDS-bearing mare flow units.

1017

1018

1019

6.4 Outstanding Questions to Address in Formulating a Young RMDS Emplacement Model

1020

1021 age for RMDSs, including: 1) If the entire population of RMDSs is so young, why are

1022 RMDS-crater embayment relationships not much more common? It is more likely that

1023 there would be a wide time range for the formation of RMDSs considering that the

1024 RMDS-bearing mare units across the whole lunar surface have a broad age diversity

1025 (e.g., Hiesinger et al., 2011; Morota et al., 2011). 2) Why do the RMDSs have the

1026 same mineralogical affinities as their host lava flows, despite being erupted billions of

1027 years later? 3) The number of extrusive lunar basalt lava flow units peaks in the

1028 Imbrian and has significantly declined by the Eratosthenian, with no significant

1029 extrusive lava flows in the Copernican (e.g., Hiesinger et al., 2011). Despite this trend,

1030 RMDSs of apparent Copernican age are extremely widespread in the major lunar

1031 maria (Figure 1) (e.g., Zhang et al., 2020); 4) The occurrence of the youngest lunar 
1032 lava flow units (Eratosthenian) is concentrated in the northern Oceanus Procellarum

1033 region (Hiesinger et al., 2011) and hypothesized to be related to the

1034 radioactive-element rich Procellarum KREEP Terrain crustal province (Jolliff et al.,

1035 2000). However, based on the RMDS distribution data (Figure 1) reported by Zhang

1036 et al. (2020), RMDSs occur in almost all other maria except the northern Oceanus

1037 Procellarum region; 5) If the RMDSs formed by Copernican-aged extrusive

1038 volcanism, what type of detailed model for the generation, ascent and eruption of

1039 magma is consistent with the emplacement of such small features and their associated

1040 moats, both individually, and in clusters, across virtually all the major maria of the

1041 Moon? 6) What global thermal evolution model(s) can account for such widespread

1042 Copernican-age volcanism? 7) Copernican-aged volcanism associated with the

1043 Irregular Mare Patches (IMPs) has been reported (Braden et al, 2014), but the ages

1044 and modes of emplacement have been debated (e.g., Qiao et al., 2017, 2019; Wilson

$1045 \&$ Head, 2017b). What are the similarities and differences between IMPs and RMDSs

1046 and how can this comparison better inform us about the nature of any

1047 Copernican-aged volcanism? These observations and characteristics then lead to a set

1048 of implications, constraints, requirements, and future research in association with

1049 models of Copernican-aged RMDS formation.

1050

$1051 \quad 6.5$ Some Requirements for a Young RMDS Emplacement Model

1052 Based on our current understanding of the geological history of the Moon

1053 (summarized most recently in Jolliff et al., 2006), thermal structure in the Copernican 
1054 is likely to be characterized by a very thick global lithosphere and a significantly

1055 compressional global state of stress in the lithosphere. Temperatures sufficiently high

1056 to induce partial melting and magma generation would occur only at great depths in

1057 the interior. Thus, during the Copernican, it would require significant volumes (a few

1058 hundred $\mathrm{km}^{3}$ ) and very high overpressures (tens of MPa) to propagate magma-filled

1059 cracks (dikes) to the lunar surface (Wilson \& Head, 2017a). The inevitable

1060 consequence of this is that when they reached the surface, such dikes would erupt

1061 large volumes of magma at initially high eruption rates (at least $10^{5} \mathrm{~m}^{3} \mathrm{~s}^{-1}$ ) to form

1062 deposits matching the morphologies of large mare lava flows and sinuous rilles (Head

$1063 \&$ Wilson, 2017). These conditions are in stark contrast to the requirements for

1064 forming RMDSs: small $\left(10^{4}-10^{5} \mathrm{~m}^{3}\right)$ volumes of magma erupted at low effusion rates

1065 (Zhang et al., 2020). Furthermore, since RMDSs generally have similar compositions

1066 to those of the mare lavas on which they are emplaced, their magma source regions

1067 would be required to have mineralogies that are the same as those characterizing the

1068 surface lavas that erupted several billion years before RMDS emplacement. Upon

1069 erupting at the surface, the lavas must be able to form one or more very small-volume,

1070 convex-upward mounds (more viscous magma?), surrounded by a moat, and not to

1071 form any associated volcanic landforms (lava flows, cones, small shields, pyroclastics,

1072 linear vents, associated graben, etc.).

1073 Garrick-Bethell and Seritan (2021) have suggested that geologically recent

1074 laccolithic intrusions beneath appropriately sized impact craters in ancient lava flows 
1075 could induce RMDS-like topography on the surface, but this model does not explain

1076 all RMDS features, especially the relatively wide moats. This explanation also suffers

1077 from the same problem as any small-volume, recent activity: the need to fine-tune the

1078 volume of magma getting close to the surface (Zhang et al., 2020). In summary, no

1079 model able to explain how recent volcanism could emplace features with the size

1080 range characterizing RMDSs exists. While further work on magma transport to the

1081 surface might help to shed light on this problem, a fundamental examination of the

1082 assumptions and interpretations that are the basis for our current understanding of the

1083 geological and thermal evolution of the Moon's deep interior (e.g., Jolliff et al., 2006)

1084 may also be warranted.

1085

1086

1087

1088

\subsection{Future Research and Exploration Designed to Address and Resolve the RMDS Age of Emplacement Conundrum}

The genesis and evolution of the RMDSs could represent the target of future

1089 lunar exploration missions guided by the testable hypotheses formulated in this work.

1090 Both robotic and human exploration missions could help unravel their age and mode

1091 of formation. Robotic exploration with stationary landers on individual RMDSs could

1092 determine the nature of the regolith and assess the presence of highly vesicular basalts

1093 and magmatic foams predicted by the "contemporaneous" model. Absolute ages could

1094 also be estimated, even allowing for low precision and a relatively large uncertainty

1095 window of hundreds of millions of years: this would suffice to resolve the Imbrian versus Copernican age predictions of the two hypotheses.

1097 Robotic rovers could traverse the domes, the moats, and the surrounding mare 
1098 terrains, searching for definitive evidence of age differences and feature (mound, moat)

1099 origins. Ground-penetrating radar, as recently employed on Chang'e 3 and 4 missions

1100 (e.g., Lai et al., 2019), would significantly help to resolve these issues (for example,

1101 detection of a post-host-unit, pre-RMDS regolith substrate layer representing

1102 accumulation during the several billion years interval predicted to occur in the

1103 Copernican-RMDS model). Robotic samples return (such as recently accomplished by

1104 Chang'e 5) from a RMDS mound summit would address most outstanding questions.

1105 Of course, the ideal exploration scenario would include human exploration, as

1106 accomplished during the Apollo Lunar Exploration Program, which would add an

1107 informed and flexible survey of stratigraphic relationships and take advantage of

1108 serendipitous opportunities. Thus, the quest for the origin and age of the RMDSs

1109 represents an important potential target for all levels of future lunar exploration.

1110

1111 7. Conclusions

1112 Ring-Moat Dome Structures (RMDSs) have recently been documented in most

1113 of the major lunar maria: they are small circular mounds (average diameter $\sim 200 \mathrm{~m}$ )

$1114 \sim 3-4 \mathrm{~m}$ in height, surrounded by narrow, shallow moats, occurring in clusters, and are

1115 widespread in ancient Imbrian-aged mare basalt host units, showing mineralogies

1116 similar to their host units. A formation model to explain the co-occurrence and related

1117 genesis of RMDSs and their host flow unit has been proposed (Wilson et al., 2019). In

1118 this emplacement model, lava flow inflation and second boiling result in significant

1119 degassing of volatiles to produce magmatic foams, and cause crustal cracking and 
1120 extrusion of foams to produce domes and their related ring moats. This model

1121 concludes that RMDS occurrences represent late-stage inflation and degassing

1122 activity in the waning stages of flow emplacement, cooling, and solidification. Thus,

1123 RMDSs are coincident in time with the emplacement of the flow, consistent with the

1124 similar mineralogy of the flow and the RMDSs.

1125 Several lines of evidence suggest, however, that the RMDS did not form

1126 contemporaneously with the host flow emplacement, but rather formed in the

1127 Copernican Period ( $\sim 1.1$ Ga to present), 1-3 billion years after the emplacement and

1128 solidification of the host lava flows. Several cases of embayment of RMDS domes

1129 into circular depressions (and thus their superposition and younger age) are reported.

1130 Based on the high likelihood that these circular depressions are of impact origin, the

1131 degradation states of the underlying embayed craters can be used to estimate the

1132 maximum age of embayment, resulting in estimate Copernican ages $(\sim 1.1 \mathrm{Ga}-$

1133 present) of mound emplacement and embayment. Additional supporting evidence for

1134 a much younger age independent of the host mare basalt unit comes from crater

1135 degradation age and regolith thickness models. The ages of the RMDS host lava flows

1136 are typically in the range of 2-3.7 Ga. Regolith development models on lunar basaltic

1137 lava flows predict that the thickness of regolith on top of lava flows of these ages

1138 should be in the 5-10 m range, comparable to the vertical relief of domes and

1139 significantly exceeding the vertical relief of the moats. The observations favor a much

1140 younger RMDS emplacement age. The synchronous emplacement model also predicts 
1141 unusual surface properties for the RMDS substrate. However, initial examination of

1142 craters superposed on RMDSs suggests that their morphologies are comparable to

1143 those occurring in normal maria.

1144 To address this fundamental age contradiction for RMDS emplacement, we

1145 outlined the detailed nature of these contradictions, described candidate requirements

1146 for a young RMDS emplacement model, and concluded with a discussion of key

1147 exploration goals and objectives that could help clarify and resolve this very

1148 significant conundrum for the geological and thermal evolution of the Moon.

1150 Data Availability Statement

1151 The imagery of LROC NACs used in this work is archived in the Geophysics

1152 Nodes of the Planetary Data System (PDS). All the over 8000 RMDSs presented in

1153 Figure 1 can be found at the Zenodo.org. (Zhang, F. et al., 2020a, Zenodo,

1154 http://doi.org/10.5281/zenodo.3711659). The NAC-based DEMs used for estimating

1155 the ages of RMDS-overlapped craters (Figs. 2a-2c, corresponding to areas A2, A4,

1156 and A7) with a locally calibrated Monte Carlo model are also available online (Zhang,

1157 F. et al., 2020b, Zenodo, http://doi.org/10.5281/zenodo.3748825).

1158

1159 Acknowledgements

1160 This research was supported by the Science and Technology Development Fund,

1161 Macau SAR (File No. 0049/2020/A1), the National Natural Science Foundation of

1162 China (Grants No. 11903090 and 11941001), and the National Key R\&D Program of

1163 China (Grant No. 2020YFE0202100). The authors would like to thank K. Fisher for 
1164 providing the crater annotation data used for CNN training. TW and CW were funded

1165 by the Deutsche Forschungsgemeinschaft (DFG, German Research Foundation),

1166 Project number 269661170. The authors would like to thank the Editor Bradley

1167 Thomson and two anonymous reviewers for their constructive comments and

1168 suggestions.

\section{References}

1170 Anthony, E. Y., \& Poths, J. (1992). 3He surface exposure dating and its

1171 implications for magma evolution in the Potrillo volcanic field, Rio Grande Rift, New

1172 Mexico, USA. Geochimica et Cosmochimica Acta, 56(11), 4105-4108.

1173 https://doi.org/10.1016/0016-7037(92)90022-B

1174 Bart, G. D., Nickerson, R. D., Lawder, M. T., \& Melosh, H. J. (2011). Global

1175 survey of lunar regolith depths from LROC images. Icarus, 215(2), 485-490.

1176 https://doi.org/10.1016/j.icarus.2011.07.017

1177 Basilevsky, A. T. (1974). Estimation of thickness and degree of reworking of

1178 lunar regolith from the crater spatial densities. Kosmicheskie Issledovaniya. V. XII.

1179 Issue 4. 606-609. (In Russian).

1180 Basilevsky, A. T. (1976). On the evolution rate of small lunar craters. In 7th Lunar

1181 and Planetary Science Conference, The Woodlands, TX, 1,005-1,020.

1182 Basilevsky, A. T., 2015. Estimation of absolute age of impact craters of the Moon, 1183 Mercury and Mars based on the degree of their morphologic prominence. In Study of

1184 the Solar system: The space milestones. Proceedings of the Scientific Session devoted

1185 to $80^{\text {th }}$ jubilee of Academician M. Ya. Marov. Space Research Institute. Moscow.

1186 213-228.

1187 Basilevsky, A. T., Florensky, C. P., \& Ronca, L. B. (1977). A possible lunar

1188 outcrop: A study of Lunokhod-2 data. The moon, 17(1), 19-28.

1189 https://doi.org/10.1007/BF00566850

1190 Basilevsky, A. T., \& Michael, G. G. (2021). Lunar Crater Ina: Analysis of the

1191 Morphology of Intercrater Landforms. Solar System Research, 55(1), 20

1192 30. https://doi.org/10.1134/S0038094621010020

1193 Basilevsky, A. T., Zhang, F., Wöhler, C., Bugiolacchi, R., Head, J. W., \& Wilson,

1194 L. (2019). Lunar Ring-Moat Dome Structures and Their Relationships with Small

1195 Impact Craters. In 50th Lunar and Planetary Science Conference, The Woodlands, TX 1196 (abstract \#1507).

1197 Bennett, K. A., Horgan, B. H. N., Bell, J. F., Meyer, H. M., \& Robinson, M. S. 1198 (2015). Moon Mineralogy Mapper investigation of the Ina irregular mare patch. In 1199 46th Lunar and Planetary Science Conference, The Woodlands, TX (abstract \#2646).

1200 Borg, L. E., Shearer, C. K., Asmerom, Y., \& Papike, J. J. (2004). Prolonged 
1201 KREEP magmatism on the Moon indicated by the youngest dated lunar igneous rock. Nature, 432(7014), 209-211. https://doi.org/10.1038/nature03070

Borg, L. E., Gaffney, A. M., \& Shearer, C. K. (2015). A review of lunar chronology revealing a preponderance of $4.34-4.37$ Ga ages. Meteoritics \& Planetary Science, 50(4), 715-732. https://doi.org/10.1111/maps.12373

Braden, S. E., Stopar, J. D., Robinson, M. S., Lawrence, S. J., Van Der Bogert, C. H., \& Hiesinger, H. (2014). Evidence for basaltic volcanism on the Moon within the past 100 million years. Nature Geoscience, 7(11), 787-791. https://doi.org/10.1038/ngeo2252

Bugiolacchi, R., \& Wöhler, C. (2020), Small craters population as a useful geological investigative tool: Apollo 17 region as a case study, Icarus, 350, 113927. https://doi.org/10.1016/j.icarus.2020.113927

De Hon, R. A., \& Earl, R. A. (2018). Reassessment of features in the Aden Crater lava flows, Dona Ana County, New Mexico. New Mexico Geology, 40(1), 17-26.

Fassett, C. I., Minton, D. A., Thomson, B. J., Hirabayashi, M., \& Watters, W. A. (2018). Re-analysis of observations of crater degradation on the lunar maria accounting for anomalous diffusion. In 49th Lunar and Planetary Science Conference, The Woodlands, TX (abstract \#1502).

Fassett, C. I., \& Thomson, B. J. (2014). Crater degradation on the lunar maria: Topographic diffusion and the rate of erosion on the Moon. Journal of Geophysical Research: Planets, 119(10), 2255-2271. https://doi.org/10.1002/2014JE004698

Fernandes, V. A., Burgess, R., Bischoff, A., Sokol, A. K., \& Haloda, J. (2007). Kalahari 009 and North East Africa 003: Young $(<2.5 \mathrm{Ga})$ lunar mare basalts. In 38th Lunar and Planetary Science Conference, The Woodlands, TX (abstract \#1611).

Fisher, K. (2014). An age for Hell Q from small diameter craters. In 45th Lunar and Planetary Science Conference, The Woodlands, TX (abstract \#1421).

Garrick-Bethell, I., \& Seritan, M. R. (2021). Laccolith model for lunar Ring-moat Dome Structures. In 52th Lunar and Planetary Science Conference, The Woodlands, TX (abstract 2369).

Garry, W. B., Robinson, M. S., Zimbelman, J. R., Bleacher, J. E., Hawke, B. R., Crumpler, L. S., et al. (2012). The origin of Ina: Evidence for inflated lava flows on the Moon. Journal of Geophysical Research: Planets, 117(E12), E00H31. https://doi.org/10.1029/2011JE003981

Gelman, A., Carlin, J. B., Stern, H. S., Dunson, D. B., Vehtari, A., \& Rubin, D. B. (2013). Bayesian data analysis. CRC press.

Greeley, R. (1970). Terrestrial analogs to lunar dimple (drainage) craters. The moon, 1(2), 237-252. https://doi.org/10.1007/BF00562828

Greeley, R., \& Gault, D. E. (1971). Endogenetic craters interpreted from crater counts on the inner wall of Copernicus. Science, 171(3970), 477-479. DOI: 10.1126/science.171.3970.477

Greeley, R., \& Gault, D. E. (1979). Endogenic craters on basaltic lava flows-Size frequency distributions. In 10th Lunar and Planetary Science Conference Proceedings, 
1243

1244

1245

1246

1247

1248

1249

1250

1251

1252

1253

1254

1255

1256

1257

1258

1259

1260

1261

1262

1263

1264

1265

1266

1267

1268

1269

1270

1271

1272

1273

1274

1275

1276

1277

1278

1279

1280

1281

1282

1283

1284

The Woodlands, TX, 2,919-2,933.

Grimes, K. G. (2008). Small Subcrustal Lava Caves: Examples from Victoria, Australia. In Proceedings of the X, XI, and XII International symposia on Vulcanospeleology, Association for Mexican Cave Studies Bulletin (Vol. 19, pp. 35-44).

Grumpe, A., \& Wöhler, C. (2014). Recovery of elevation from estimated gradient fields constrained by digital elevation maps of lower lateral resolution. ISPRS Journal of Photogrammetry and Remote Sensing, 94, 37-54.

https://doi.org/10.1016/j.isprsjprs.2014.04.011

Grumpe, A., Schröer, C., Kauffmann, S., Fricke, T., Wöhler, C., \& Mall, U. (2016). Refinement of stereo image analysis using photometric shape recovery as an alternative to bundle adjustment. International Archives of the Photogrammetry, Remote Sensing \& Spatial Information Sciences, vol. XLI-B4, p. 565-572.

Hamilton, C. W., Scheidt, S. P., Sori, M. M., de Wet, A. P., Bleacher, J. E., Mouginis-Mark, P. J., et al. (2020). Lava-Rise Plateaus and Inflation Pits in the McCartys Lava Flow Field, New Mexico: An Analog for Pāhoehoe-Like Lava Flows on Planetary Surfaces. Journal of Geophysical Research: Planets, 125(7), e2019JE005975. https://doi.org/10.1029/2019JE005975

Hartmann, W. K., Quantin, C., \& Mangold, N. (2007). Possible long-term decline in impact rates: 2. Lunar impact-melt data regarding impact history. Icarus, 186(1), 11-23. https://doi.org/10.1016/j.icarus.2006.09.009

Head, J. W. (1976). Lunar volcanism in space and time. Reviews of Geophysics, 14(2), 265-300. https://doi.org/10.1029/RG014i002p00265

Head, J. W., \& Ivanov, B. A. (2019). Ina irregular mare patch (IMP): New insights from observations of superposed impact craters. The $10^{\text {th }}$ Moscow Solar System Symposium, Space Research Institute, Moscow, Russia, abstract \#MS3-PS-32.

Head, J. W., \& Wilson, L. (2017). Generation, ascent and eruption of magma on the Moon: New insights into source depths, magma supply, intrusions and effusive/explosive eruptions (Part 2: Predicted emplacement processes and observations). Icarus, 283, 176-223. https://doi.org/10.1016/j.icarus.2016.05.031

Head, J. W., \& Wilson, L. (2020). Rethinking lunar mare basalt regolith formation: new concepts of lava flow protolith and evolution of regolith thickness and internal structure. Geophysical Research Letters, 47(20), e2020GL088334. https://doi.org/10.1029/2020GL088334

Hess, P. C., \& Parmentier, E. M. (1995). A model for the thermal and chemical evolution of the Moon's interior: Implications for the onset of mare volcanism. Earth and Planetary Science Letters, 134(3-4), 501-514. https://doi.org/10.1016/0012-821X(95)00138-3

Hiesinger, H., Head, J. W., Wolf, U., Jaumann, R., \& Neukum, G. (2006). New ages for basalts in Mare Fecunditatis based on crater size-frequency measurements. In 37th Lunar and Planetary Science Conference, The Woodlands, TX (abstract \#1151).

Hiesinger, H., Head, J. W., Wolf, U., Jaumann, R., \& Neukum, G. (2011). Ages 
1285

1286

1287

1288

1289

1290

1291

1292

1293

1294

1295

1296

1297

1298

1299

1300

1301

1302

1303

1304

1305

1306

1307

1308

1309

1310

1311

1312

1313

1314

1315

1316

1317

1318

1319

1320

1321

1322

1323

1324

1325

1326

and stratigraphy of lunar mare basalts: A synthesis. Recent Advances and Current Research Issues in Lunar Stratigraphy: Geological Society of America Special Paper, 477, 1-51. DOI: 10.1130/2011.2477(01)

Hoffer, J. M. (1976). Geology of the Potrillo basalt field, south-central New Mexico. New Mexico Bureau of Mines and Mineral Resources, Circular 149, 1-30.

Hon, K. E. N., Kauahikaua, J. I. M., Denlinger, R., \& Mackay, K. (1994). Emplacement and inflation of pahoehoe sheet flows: Observations and measurements of active lava flows on Kilauea Volcano, Hawaii. Geological Society of America Bulletin, 106(3), 351-370. https://doi.org/10.1130/0016-7606(1994)106<0351:EAIOPS >2.3.CO;2

Jolliff, B. L., Gillis, J. J., Haskin, L. A., Korotev, R. L., \& Wieczorek, M. A. (2000). Major lunar crustal terranes: Surface expressions and crust-mantle origins. Journal of Geophysical Research: Planets, 105(E2), 4197-4216. https://doi.org/10.1029/1999JE001103

Joliff, B., Wieczorek, M., Shearer, C., Neal, C. (Eds.). (2006). New views of the Moon. Vol. 60 of Reviews in mineralogy \& geochemistry. Mineralogical Society of America and the Geochemical Society.

Kreslavsky, M. A., Head, J. W., Neumann, G. A., Zuber, M. T., \& Smith, D. E. (2017). Low-amplitude topographic features and textures on the Moon: Initial results from detrended Lunar Orbiter Laser Altimeter (LOLA) topography. Icarus, 283, 138-145. https://doi.org/10.1016/j.icarus.2016.07.017

Lai, J., Xu, Y., Zhang, X., Xiao, L., Yan, Q., Meng, X., et al. (2019). Comparison of Dielectric Properties and Structure of Lunar Regolith at Chang'e-3 and Chang'e-4 Landing Sites Revealed by Ground-Penetrating Radar. Geophysical Research Letters, 46(22), 12,783-12,793. https://doi.org/10.1029/2019GL084458

McEwen, A. S., \& Bierhaus, E. B. (2006). The importance of secondary cratering to age constraints on planetary surfaces. Annual Review of Earth and Planetary Science, 34, 535-567. https://doi.org/10.1146/annurev.earth.34.031405.125018

McKay, D. S., Heiken G., Basu A, Blanford G., Simon S., Reedy R., French B. M., \& Papike J. (1991). The lunar regolith. In: Lunar Source Book: A User Guide to the Moon. G.H. Heiken, D.T. Vaniman, B.M. French eds., Cambridge University Press, 285-356.

Morota, T., Haruyama, J., Ohtake, M., Matsunaga, T., Honda, C., Yokota, Y., et al. (2011). Timing and characteristics of the latest mare eruption on the Moon. Earth and Planetary Science Letters, 302(3-4), 255-266.

https://doi.org/10.1016/j.epsl.2010.12.028

Neukum, G., Ivanov, B., \& Hartmann, W. (2001). Cratering records in the inner solar system in relation to the lunar reference system. Space Science Reviews, 96, 5586. https:// doi.org/10.1023/A:1011989004263.

Ollier, C. D. (1964). Tumuli and lava blisters of Victoria, Australia. Nature, 202(4939), 1284-1286. https://doi.org/10.1038/2021284a0

Qiao, L., Head, J., Wilson, L., Xiao, L., Kreslavsky, M., \& Dufek, J. (2017). Ina 
1327

1328

1329

1330

1331

1332

1333

1334

1335

1336

1337

1338

1339

1340

1341

1342

1343

1344

1345

1346

1347

1348

1349

1350

1351

1352

1353

1354

1355

1356

1357

1358

1359

1360

1361

1362

1363

1364

1365

1366

1367

1368

pit crater on the Moon: Extrusion of waning-stage lava lake magmatic foam results in extremely young crater retention ages. Geology, 45(5), 455-458.

https://doi.org/10.1130/G38594.1

Qiao, L., Head, J. W., Ling, Z., Wilson, L., Xiao, L., Dufek, J. D., \& Yan, J. (2019). Geological characterization of the Ina shield volcano summit pit crater on the Moon: Evidence for extrusion of waning-stage lava lake magmatic foams and anomalously young crater retention ages. Journal of Geophysical Research: Planets, 124(4), 1100-1140. https://doi.org/10.1029/2018JE005841

Robinson, M. S., Brylow, S. M., Tschimmel, M., Humm, D., Lawrence, S. J., Thomas, P. C., et al. (2010). Lunar reconnaissance orbiter camera (LROC) instrument overview. Space Science Reviews, 150(1-4), 81-124.

https://doi.org/10.1007/s11214-010-9634-2

Schultz, P. H., \& Greeley, R. (1976). Ring-moat structures: Preserved flow morphology on lunar maria. In 7th Lunar and Planetary Science Conference, The Woodlands, TX, 788-789.

Schultz, P. H., Greeley, R., \& Gault, D. (1976). Degradation of small mare surface features. In 7th Lunar and Planetary Science Conference, The Woodlands, TX, 9851003.

Schultz, P. H., \& Spudis, P. D. (1983). Beginning and end of lunar mare volcanism. Nature, 302(5905), 233-236. https://doi.org/10.1038/302233a0

Schultz, P. H., Staid, M. I., \& Pieters, C. M. (2006). Lunar activity from recent gas release. Nature, 444(7116), 184-186. https://doi.org/10.1038/nature05303

Self, S., Keszthelyi, L., \& Thordarson, T. (1998). The importance of pāhoehoe. Annual Review of Earth and Planetary Sciences, 26(1), 81-110. https://doi.org/10.1146/annurev.earth.26.1.81

Shearer, C. K., Hess, P. C., Wieczorek, M. A., Pritchard, M. E., Parmentier, E. M., Borg, L. E., et al. (2006). Thermal and magmatic evolution of the Moon. Reviews in Mineralogy and Geochemistry, 60(1), 365-518. https://doi.org/10.2138/rmg.2006.60.4

Shkuratov, Y. G., \& Bondarenko, N. V. (2001). Regolith layer thickness mapping of the Moon by radar and optical data. Icarus, 149(2), 329-338.

https://doi.org/10.1006/icar.2000.6545

Shoemaker, E. M., Batson, R. M., Holt, H. E., Morris, E. C., Rennilson, J. J., \& Whitaker, E. A. (1969). Observations of the lunar regolith and the Earth from the television camera on Surveyor 7. Journal of Geophysical Research, 74(25), 6081-6119. https://doi.org/10.1029/JB074i025p06081

Sinha, R. K., Sivaprahasam, V., Bhatt, M., Kumari, N., Srivastava, N., Varatharajan, I., et al. (2020). Geological characterization of Chandrayaan-2 landing site in the southern high latitudes of the Moon. Icarus, 337, 113449. https://doi.org/10.1016/j.icarus.2019.113449

Snoek, J., Larochelle, H., \& Adams, R. P. (2012). Practical Bayesian Optimization of Machine Learning Algorithms. Preprint, arXiv:1206.2944.

https://arxiv.org/abs/1206.2944v2 
1369

1370

1371

1372

1373

1374

1375

1376

1377

1378

1379

1380

1381

1382

1383

1384

1385

1386

1387

1388

1389

1390

1391

1392

1393

1394

1395

1396

1397

1398

1399

1400

1401

1402

1403

1404

1405

1406

1407

1408

1409

1410

Solomon, S. C. (1978). On volcanism and thermal tectonics on one-plate planets. Geophysical Research Letters, 5(6), 461-464.

https://doi.org/10.1029/GL005i006p00461

Solomon, S. C. (1986). On the early thermal state of the Moon. In Hartmann, W. K., et al., eds., Origin of the Moon, Houston, Texas, Lunar and Planetary Institute, 435-452.

Spohn, T., Konrad, W., Breuer, D., \& Ziethe, R. (2001). The longevity of lunar volcanism: Implications of thermal evolution calculations with 2D and 3D mantle convection models. Icarus, 149, 54-65. https://doi.org/10.1006/icar.2000.6514

Stöffler, D., Ryder, G., Ivanov, B. A., Artemieva, N. A., Cintala, M. J., \& Grieve, R. A. (2006). Cratering history and lunar chronology. Reviews in Mineralogy and Geochemistry, 60(1), 519-596. https://doi.org/10.2138/rmg.2006.60.05

Swann G. A., Bailey N. G., Batson R. M., Freeman, V. L., Hait, M. H., Head, J. W., et al. (1972). Preliminary Geologic Investigation of the Apollo 15 Landing Site. In: APOLLO 15 PRELIMINARY SCIENCE REPORT. NASA. Washington, D.C. 5-1 5-112.

Taylor, L. A., Shervais, J. W., Hunter, R. H., Shih, C. Y., Bansal, B. M., Wooden, J., et al. (1983). Pre-4.2 AE mare-basalt volcanism in the lunar highlands. Earth and Planetary Science Letters, 66, 33-47. https://doi.org/10.1016/0012-821X(83)90124-3

Terada, K., Anand, M., Sokol, A. K., Bischoff, A., \& Sano, Y. (2007). Cryptomare magmatism 4.35 Gyr ago recorded in lunar meteorite Kalahari 009. Nature, 450(7171), 849-852. https://doi.org/10.1038/nature06356

Van der Bogert, C. H., Michael, G., Kneissl, T., Hiesinger, H., \& Pasckert, J. H. (2015). Development of guidelines for recommended lunar CSFD count area sizes via analysis of random CSFDs. Workshop on Issues in Crater Studies and the Dating of Planetary Surfaces, abstract \#9023.

Wagner, R. V., Speyerer, E. J., Robinson, M. S., \& Team, L.R.O.C., 2015. New mosaicked data products from the LROC team. In 46th Lunar and Planetary Science Conference. The Woodlands, TX (abstract 1473).

Walker, G. P. 1991. Structure, and origin by injection of lava under surface crust, of tumuli,"lava rises", "lava-rise pits", and "lava-inflation clefts" in Hawaii. Bulletin of Volcanology, 53(7), 546-558. https://doi.org/10.1007/BF00298155

Wieczorek, M. A., Jolliff, B. L., Khan, A., Pritchard, M. E., Weiss, B. P., Williams, J. G., et al. (2006). The constitution and structure of the lunar interior. Reviews in Mineralogy and Geochemistry, 60(1), 221-364. https://doi.org/10.2138/rmg.2006.60.3

Wilhelm, T., \& Wöhler, C. (2021). Uncertainty Guided Recognition of Tiny Craters on the Moon. Proc. Int. Conf. on Pattern Recognition, pp. 5198-5205, Milano, Italy (online).

Williams, D. A., Fagents, S. A., \& Greeley, R. (2000). A reassessment of the emplacement and erosional potential of turbulent, low-viscosity lavas on the Moon. Journal of Geophysical Research: Planets, 105(E8), 20189-20205.

https://doi.org/10.1029/1999JE001220 
1411 Williams, J. P., van der Bogert, C. H., Pathare, A. V., Michael, G. G., Kirchoff, M.

1412 R., \& Hiesinger, H. (2018). Dating very young planetary surfaces from crater statistics:

1413 A review of issues and challenges. Meteoritics \& Planetary Science, 53(4), 554-582.

1414 https://doi.org/10.1111/maps.12924

1415 Wilson, L., \& Head, J. W. (2017a). Generation, ascent and eruption of magma on

1416 the Moon: New insights into source depths, magma supply, intrusions and

1417 effusive/explosive eruptions (Part 1: Theory). Icarus, 283, 146-175.

1418 https://doi.org/10.1016/j.icarus.2015.12.039

1419 Wilson, L., \& Head, J. W. (2017b). Eruption of magmatic foams on the Moon:

1420 Formation in the waning stages of dike emplacement events as an explanation of

1421 "irregular mare patches". Journal of Volcanology and Geothermal Research, 335,

1422 113-127. https://doi.org/10.1016/j.jvolgeores.2017.02.009

1423 Wilson, L., \& Head, J. W. (2018). Controls on lunar basaltic volcanic eruption

1424 structure and morphology: Gas release patterns in sequential eruption phases.

1425 Geophysical Research Letters, 45(12), 5852-5859.

1426 https://doi.org/10.1029/2018GL078327

1427 Wilson, L., Head, J. W., \& Zhang, F. (2019). A theoretical model for the formation

1428 of Ring Moat Dome Structures: Products of second boiling in lunar basaltic lava

1429 flows. Journal of Volcanology and Geothermal Research, 374, 160-180.

1430 https://doi.org/10.1016/j.jvolgeores.2019.02.018

1431 Xiao, Z., \& Werner, S. C. (2015). Size-frequency distribution of crater

1432 populations in equilibrium on the Moon. Journal of Geophysical Research: Planets,

1433 120(12), 2277-2292. https://doi.org/10.1002/2015JE004860

1434 Xie, M., Zhu, M. H., Xiao, Z., Wu, Y., \& Xu, A. (2017). Effect of topography

1435 degradation on crater size-frequency distributions: Implications for populations of

1436 small craters and age dating. Geophysical Research Letters, 44(20), 10,171-10,179.

1437 https://doi.org/10.1002/2017GL075298

1438 Zhang, F., Head, J. W., Basilevsky, A. T., Bugiolacchi, R., Komatsu, G., Wilson,

1439 L., et al. (2017). Newly discovered ring-moat dome structures in the lunar maria:

1440 Possible origins and implications. Geophysical Research Letters, 44(18), 9216-9224.

1441 https://doi.org/10.1002/2017GL074416

1442 Zhang, F., Wöhler, C., Head, J. W., Bugiolacchi, R., Wilson, L., \& Grumpe, A.

1443 (2018). Ring-Moat Dome Structures (RMDSs) in the Lunar Maria: Further Statistical

1444 and Morphological Characterization. In 49th Lunar and Planetary Science

1445 Conference, The Woodlands, TX (abstract \#1374).

1446 Zhang, F., Head, J. W., Wöhler, C., Bugiolacchi, R., Wilson, L., Basilevsky, A. T.,

1447 et al. (2020). Ring-Moat Dome Structures (RMDSs) in the lunar maria: Statistical,

1448 compositional, and morphological characterization and assessment of theories of

1449 origin. Journal of Geophysical Research: Planets, 125(7), e2019JE005967.

1450 https://doi.org/10.1029/2019JE005967

1451 Zhang, F., Head, J. W., Wöhler, C., Bugiolacchi, R., Wilson, L., Basilevsky, A. T.,

1452 et al. (2020a). Locations and derived diameters of RMDSs as per Fig. 6 and all the 
14538281 RMDSs identified so far across the global Moon by March, 2020 [Data set].

1454 Zenodo. http://doi.org/10.5281/zenodo.3711659

1455

Zhang, F., Head, J. W., Wöhler, C., Bugiolacchi, R., Wilson, L., Basilevsky, A. T.,

1456 et al. (2020b). LROC NAC-based high-resolution ( $2 \mathrm{~m}$ per pixel) digital elevation

1457 models (DEMs) of twelve regions on the Moon containing ring-moat dome structures

1458 (RMDSs) [Data set]. Zenodo. http://doi.org/10.5281/zenodo.3748825

1459 Ziethe, R., Seiferlin, K., \& Hiesinger, H. (2009). Duration and extent of lunar

1460 volcanism: Comparison of 3D convection models to mare basalt ages. Planetary and

1461 Space Science, 57(7), 784-796. https://doi.org/10.1016/j.pss.2009.02.002 
1462 Figures Captions:

1463

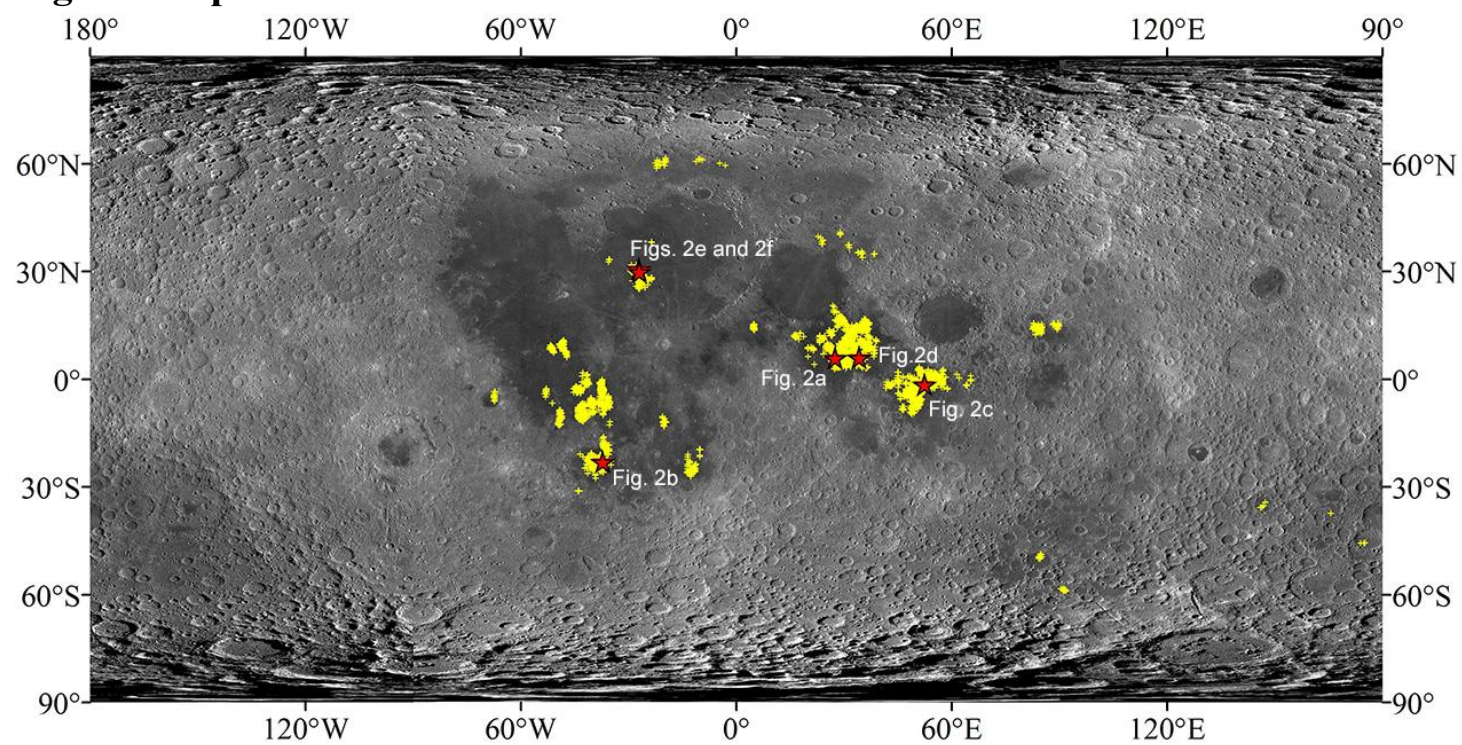

1464 Figure 1. The global distribution of more than 8,000 RMDSs (yellow crosses) on the

1465 Moon (Zhang et al., 2020). The red stars indicate the locations of the

1466 RMDS-superposed craters analyzed in this study, as shown in Figure 2. The base map

1467 is the LROC WAC Global Morphology Mosaic $100 \mathrm{~m}$ (at $643 \mathrm{~nm}$; Wagner et al., 1468 2015). 


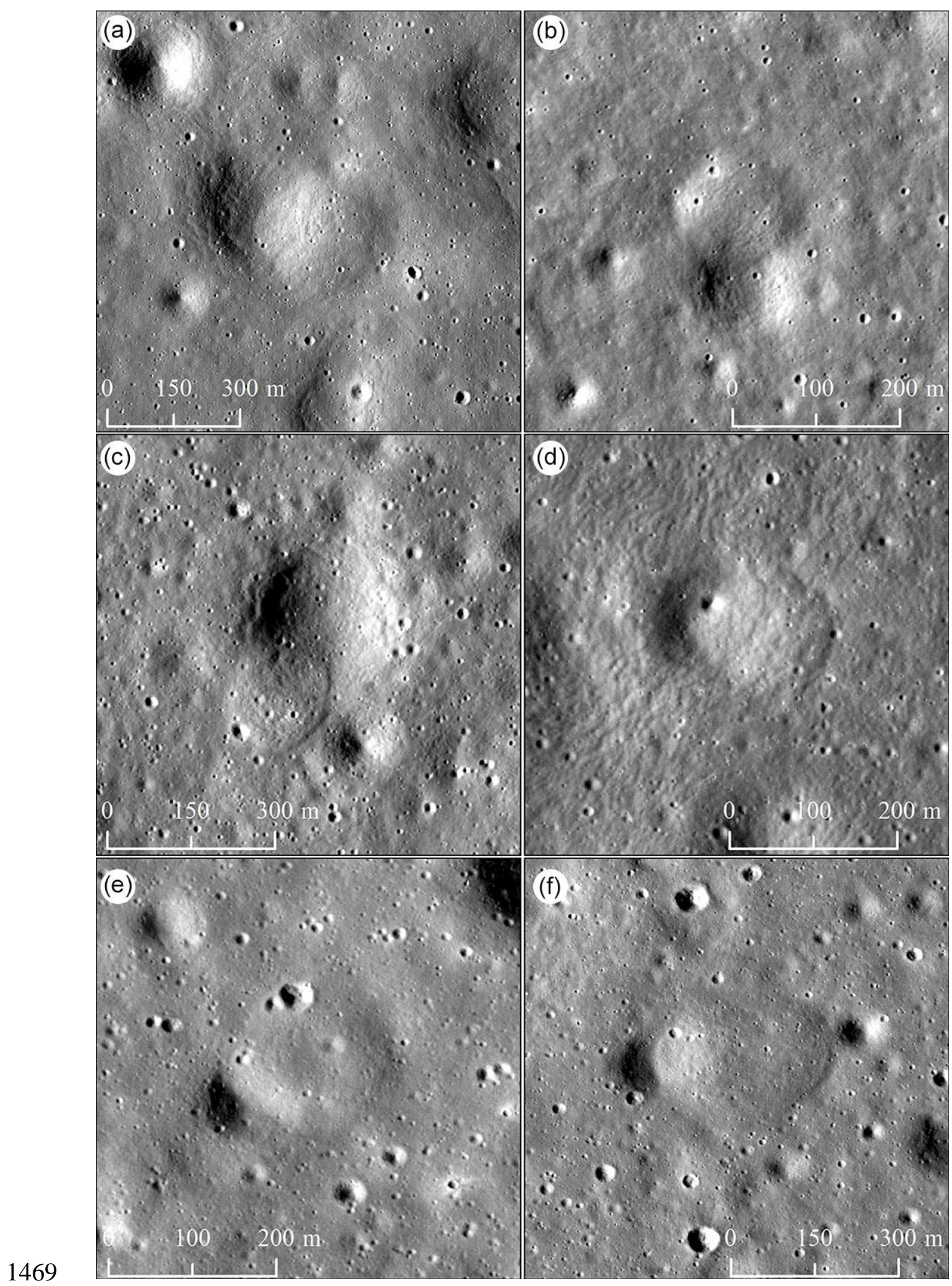

1470 Figure 2. LROC NAC images for confirmed RMDS-superposed craters analyzed in

1471 this study. Their location coordinates, hosting mare, and NAC frame used are: (a)

$1472\left(5.935^{\circ} \mathrm{N}, 27.456^{\circ} \mathrm{E}\right)$, Tranquillitatis, M1172873803LE; (b) $\left(22.967^{\circ} \mathrm{S}, 37.294^{\circ} \mathrm{W}\right)$,

1473 Humorum, M1142680981LE; (c) (1.461 $\left.{ }^{\circ} \mathrm{S}, 52.39^{\circ} \mathrm{E}\right)$, Fecunditatis, M1126787189LE; 
1474 (d) $\left(6.028^{\circ} \mathrm{N}, 34.19^{\circ} \mathrm{E}\right)$, Tranquillitatis, M180944663RE; (e) $\left(30.704^{\circ} \mathrm{N}, 27.222^{\circ} \mathrm{W}\right)$,

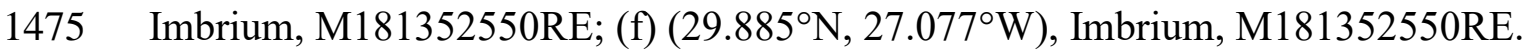

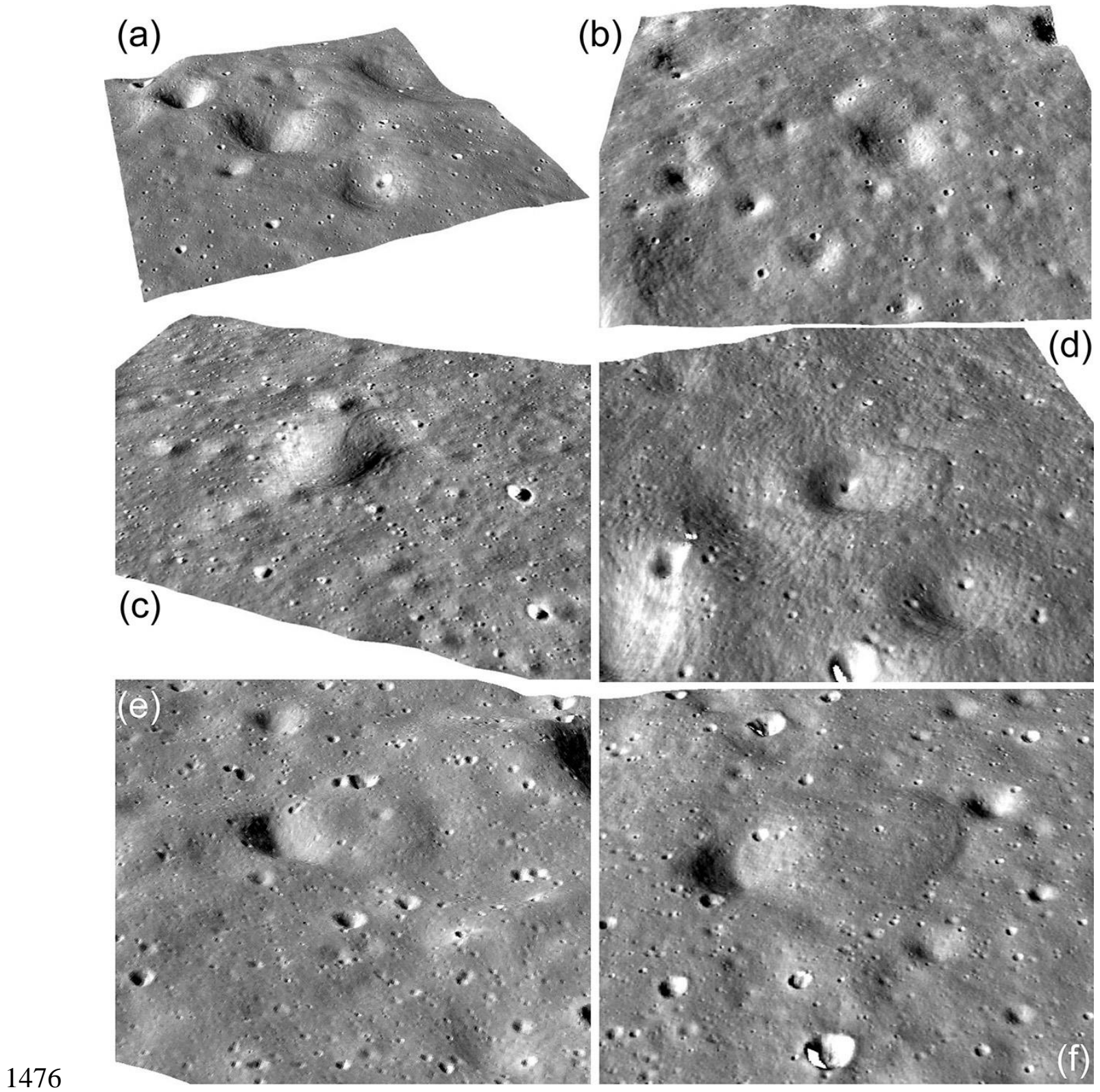

1477 Figure 3. Three-dimensional views of RMDSs embayment into adjacent craters,

1478 corresponding to the individual cases illustrated in Figure 2. The 3D views are created

1479 based on NACs draping over NAC-based DEMs ( 2 m/pixel, $6 \times$ vertical

1480 exaggeration). 


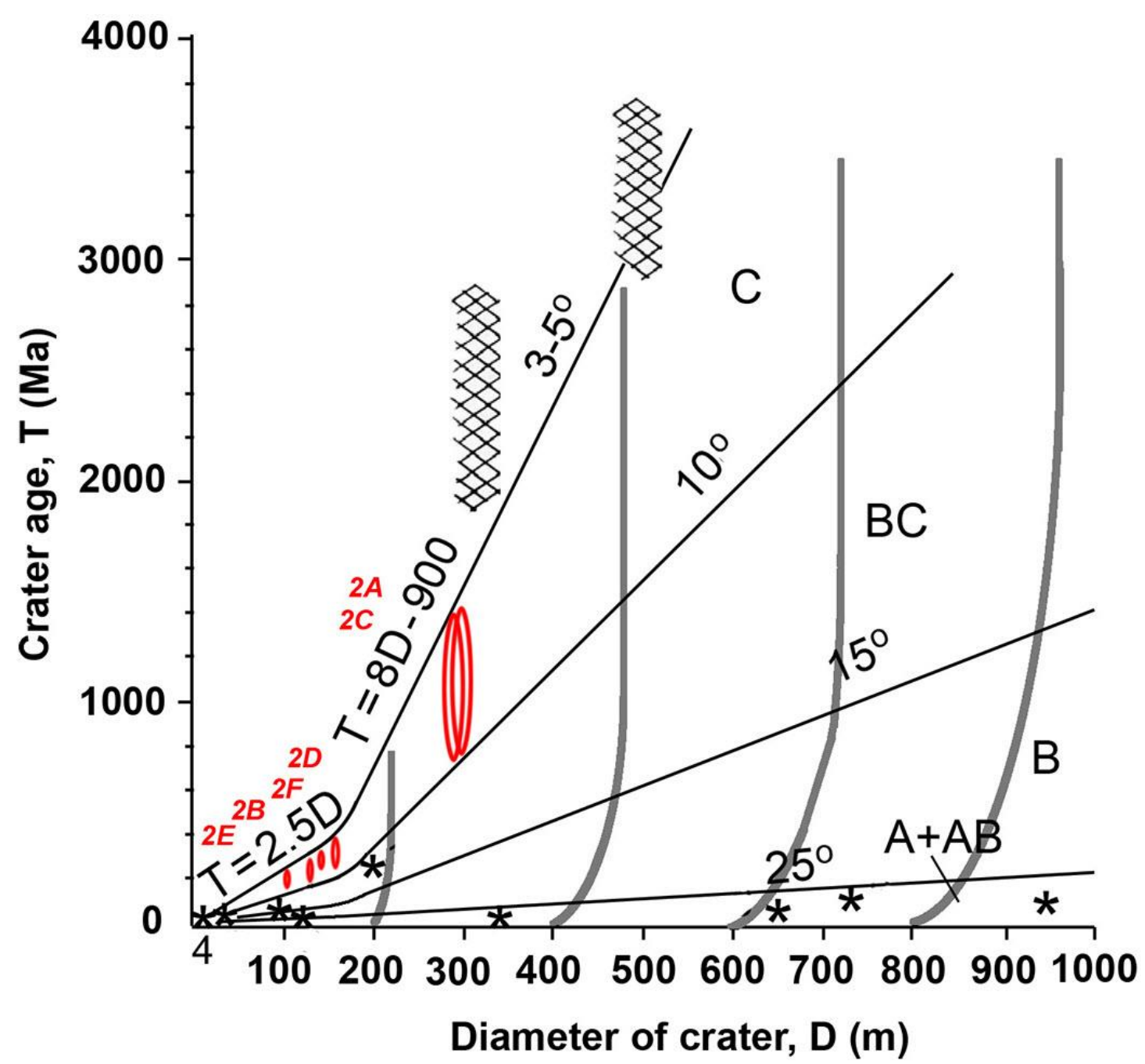

Figure 4. Ages of craters superposed by RMDS (red) on the diagram of the dependence of absolute age of craters on their diameters and the degree of their morphologic maturity - classes $\mathrm{A}, \mathrm{AB}, \mathrm{B}, \mathrm{BC}$ and $\mathrm{C}$. The typical values of maximum steepness of inner slopes of craters of different classes are shown along with the boundary lines. Asterisks show absolute ages of craters in the Apollo landing sites Cross-shaded symbols indicate the crater lifetimes deduced from crystallization ages of mare lavas (Trask, 1971). Thick gray lines show trajectories of changing of crater diameters in the process of their maturation. (Modified from Basilevsky, 1976, 2015). 

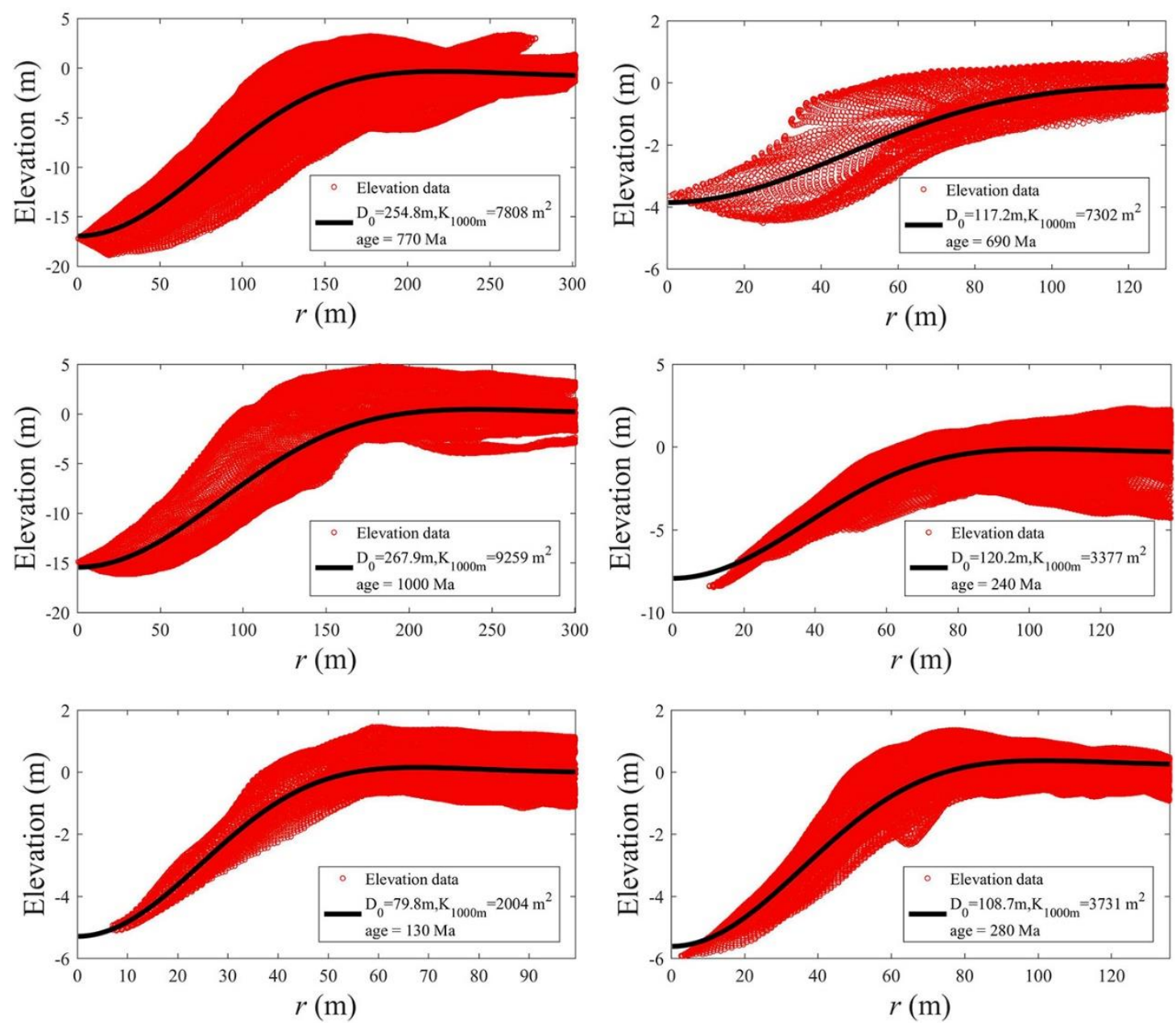

Figure 5. The crater profiles (the black curves) best-fit to the observed crater profiles (the red circles) extracted from NAC-based DTMs, corresponding to the individual cases illustrated in Figure 2. The ages of RMDS-superposed craters range from 130 to $1000 \mathrm{Ma} . \mathrm{D}_{0}$ is the original diameter, and $\mathrm{K}_{1000 \mathrm{~m}}$ is the diffusion age of a crater with a diameter of $1000 \mathrm{~m}$ derived by using Equation (2) in this study.
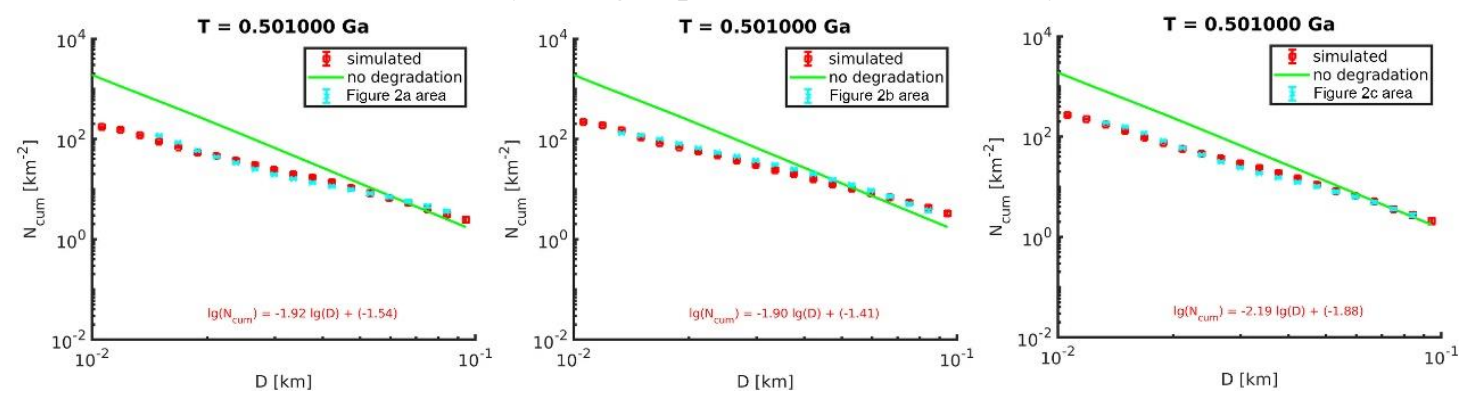

1497 Figure 6. Modeled vs. simulated CSFDs in equilibrium after 0.5 Ga for square sub-regions of about $60 \mathrm{~km}^{2}$ located inside the areas containing the RMDS-impact crater embayment respectively shown in Figures 2a-2c, obtained with the median values of $\kappa_{10}$ and $\kappa_{100}$ inferred by Bayesian optimization, respectively. The green lines correspond to the degradation-free CSFDs following from Neukum et al. (2001). 


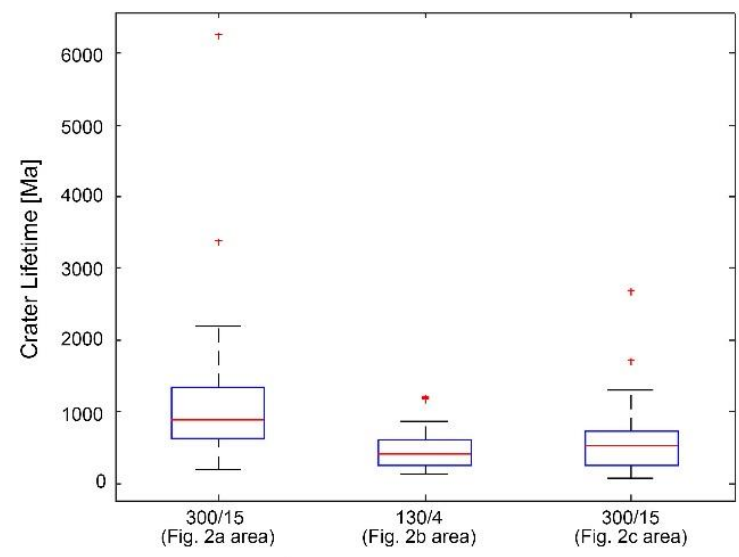

RMDS-overlapped crater (Diameter/depth)

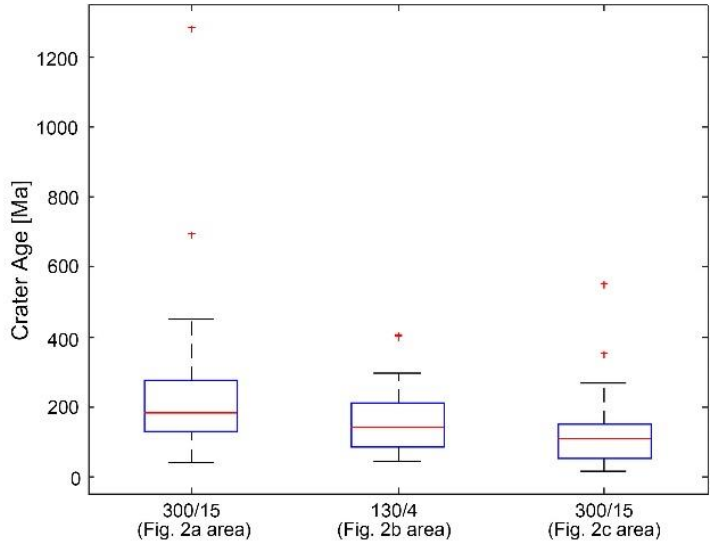

RMDS-overlapped crater (Diameter/depth)

1503 Figure 7. Boxplot representations of the crater lifetimes and ages for the

1504 RMDS-overlapped craters, as shown in Figures 2a-2c, respectively. Red lines denote

1505 median values, blue boxes the $25 \%$ and $75 \%$ quantiles, and whiskers the most

1506 extreme values of the distribution which are not outliers. Red crosses mark outliers,

1507 where the Bayesian optimization was unable to find a solution.

1508

1509

1510

1511

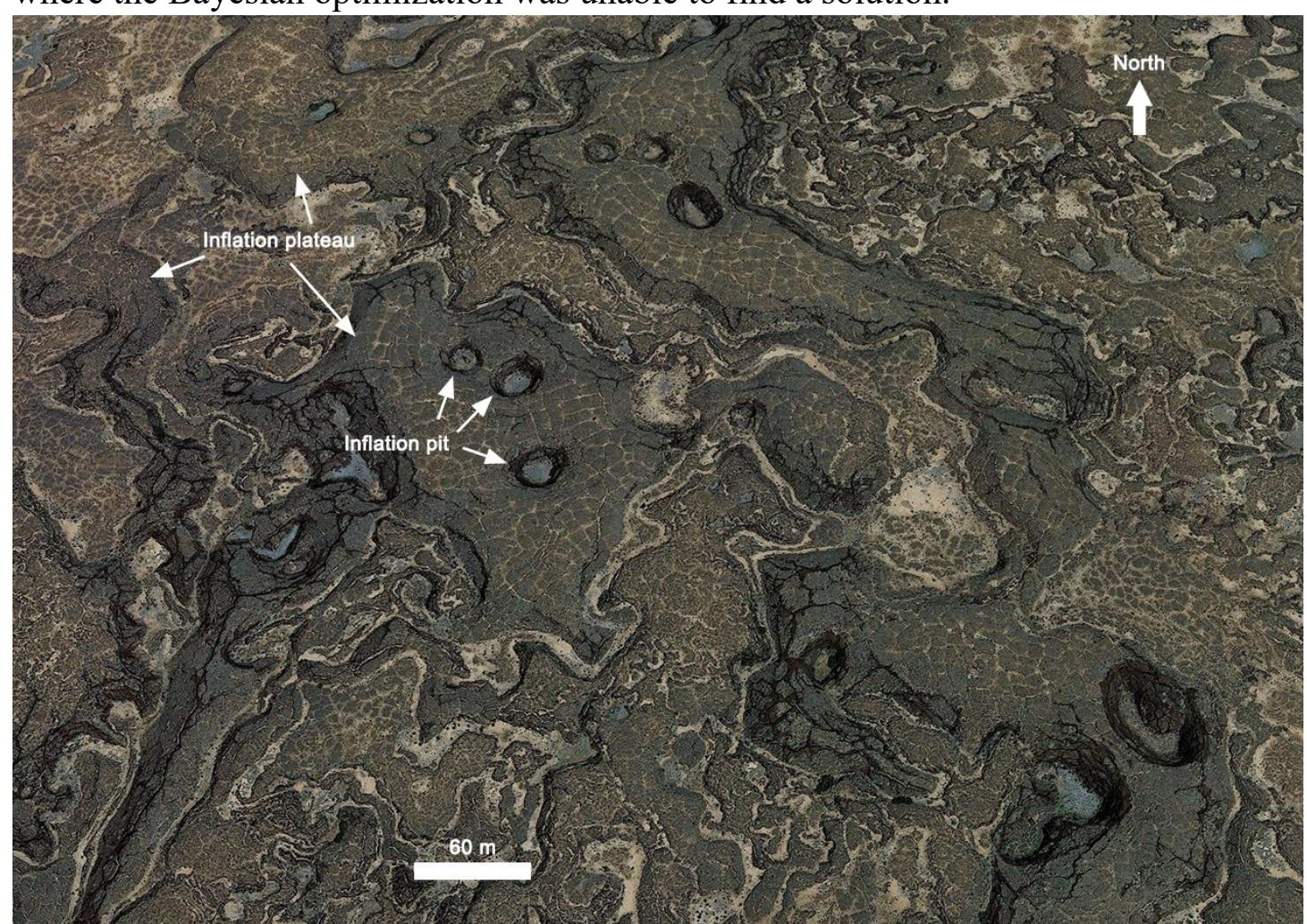

Figure 8. Terrestrial analogs of crater-like formations: Above aerial view of a group of circular depressions interpreted as lava-rise (or inflation) pits (De Hon \& Earl, 2018), Aden Basalt. Satellite image credit: Google Earth. 


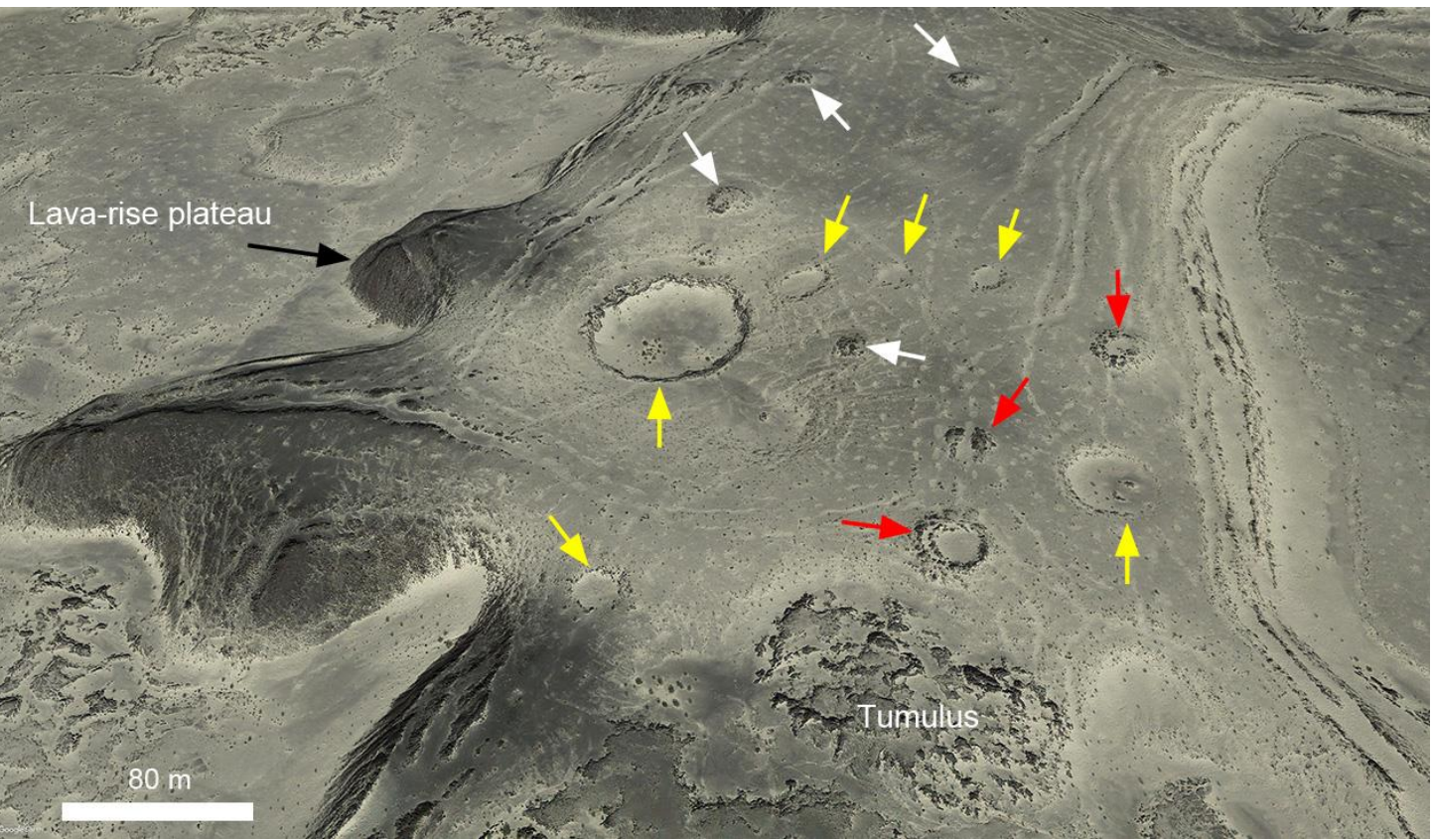

Figure 9. Oblique view of a series of positive and negative features on inflation

1514 (pressure, or lava-rise) plateau surface in the inflated Amboy lava flow field (Location:

$\left.151534.5330^{\circ} \mathrm{N}, 115.8220^{\circ} \mathrm{W}\right)$, Mojave Desert, California. Yellow arrows indicate

1516 crater-like forms, while white arrows point to nearly circular tumulus-like structures.

1517 Red arrows illustrate three tumulus-like structures that have been degraded to varying

1518 degrees. The red arrow in the bottom presents a raised rim crater interpreted in this

1519 study as a collapsed tumulus. Image credit: Google Earth. North is up.
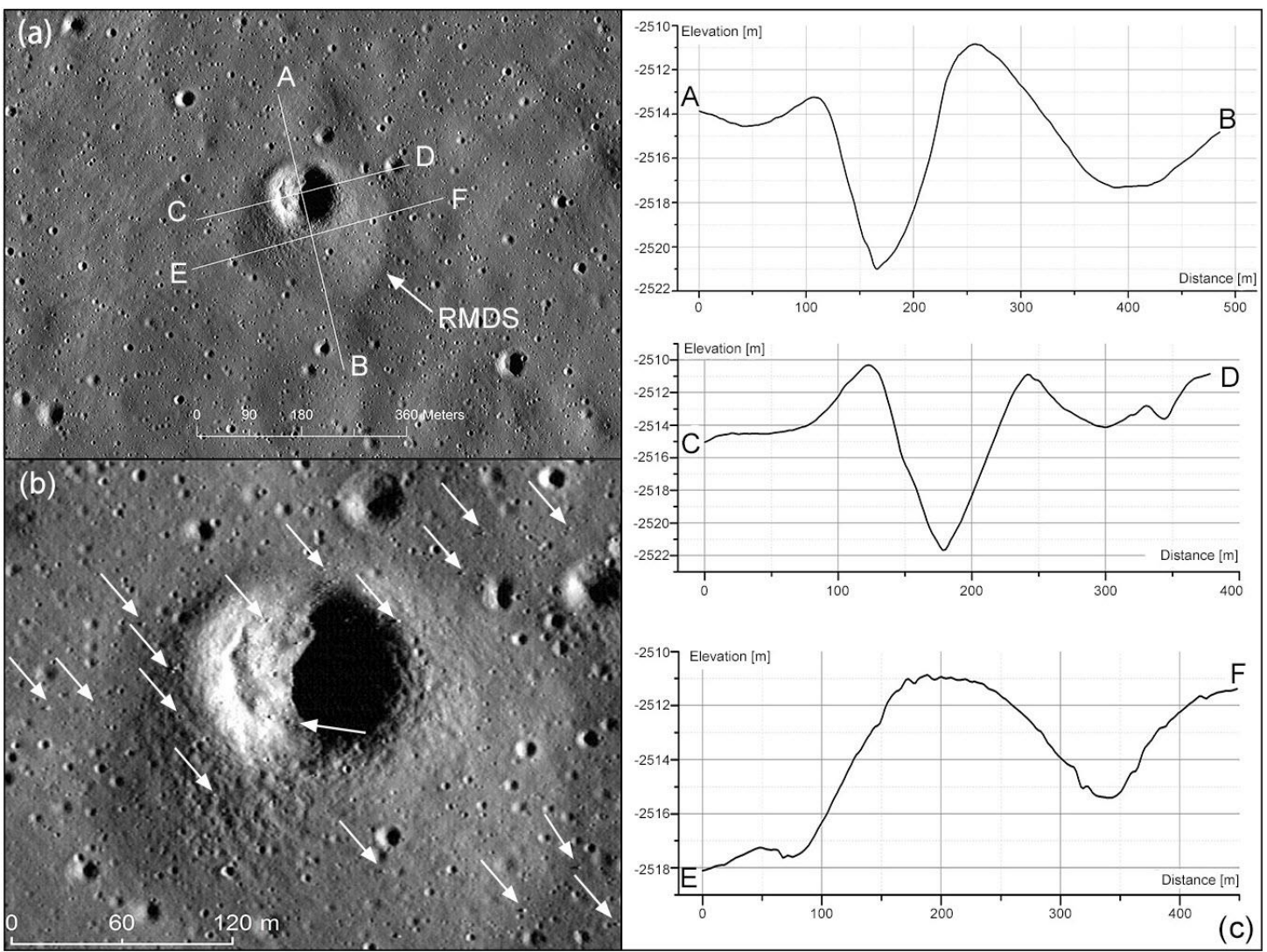
Figure 10. The 120-m crater is superposed on the northern part of a $270 \mathrm{~m}$ RMDS in Mare Fecunditatis (NAC frame: M131284180LE). (a) The RMDS-Crater relationship seen from LROC NAC with sun illumination direction from right to left. (b) The presence of meter-sized rock boulders (white arrows) on the crater rim and floor. (c) NAC-DEM-based topographic files extracted along the white lines AB, CD, and EF indicated in Figure (a). North is up in Figures (a) and (b).

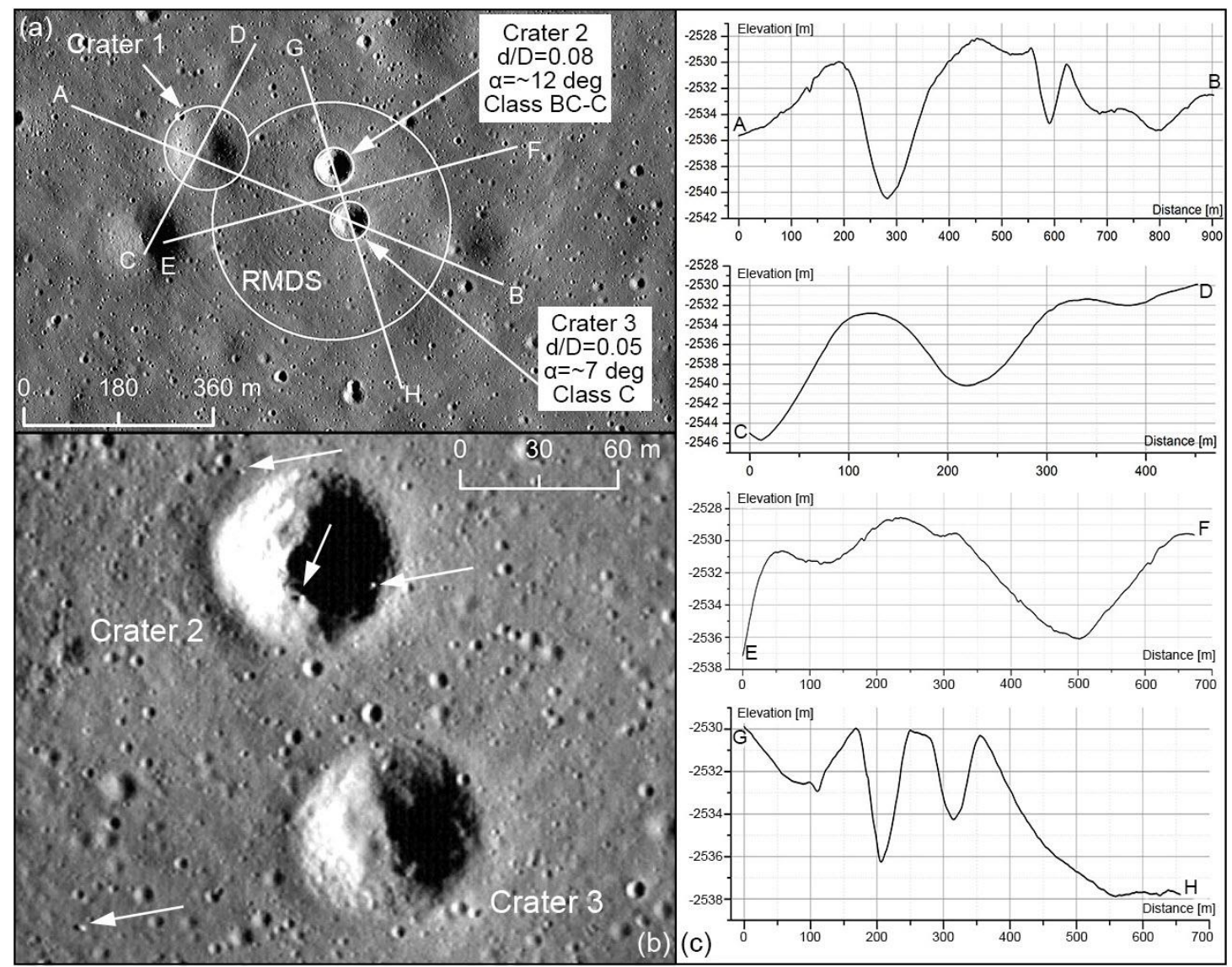

Figure 11. Three craters, 170, 80 and $80 \mathrm{~m}$ in diameter are superposed on a $\sim 450-\mathrm{m}$ RMDS in Mare Fecunditatis (NAC frame: M131284180RE). (a) The RMDS-Crater relationship seen from LROC NAC with sun illumination direction from right to left. (b) Meter-sized rock boulders (white arrows) are seen on the rim and floor of crater 2. (c) NAC-DEM-based topographic files extracted along the white lines AB, CD, EF, and GH indicated in Figure (a). North is up in Figures (a) and (b). 
1543 Table 1. Diffusion rates $\kappa_{10}$ and $\kappa_{100}$ for craters of 0.01 and $0.1 \mathrm{~km}$ diameter,

1544 respectively, for the three areas located close to the RMDS-overlapped craters in

1545 Figures 2a-2c, as derived with the locally calibrated diffusion-based method described

1546 in section 4.3. The values correspond to the median over 30 simulation runs and $25 \%$

1547 and $75 \%$ quantiles, respectively.

\begin{tabular}{|l|c|c|}
\hline area & $\boldsymbol{\kappa}_{\mathbf{1 0}}\left[\mathbf{m}^{\mathbf{2}} / \mathbf{M a}\right]$ & $\boldsymbol{\kappa}_{\mathbf{1 0 0}}\left[\mathbf{m}^{\mathbf{2}} / \mathbf{M a}\right]$ \\
\hline Fig. 2a & $2.21_{-0.29}^{+0.35}$ & $11.6_{-2.99}^{+2.03}$ \\
\hline Fig. 2b & $1.91_{-0.39}^{+0.62}$ & $8.24_{-2.31}^{+4.51}$ \\
\hline Fig. 2c & $1.44_{-0.41}^{+0.39}$ & $14.2_{-2.21}^{+7.45}$ \\
\hline
\end{tabular}

1548

1549 Table 2. Statistical results for the diameter (D), depth (d), and inner slope ( $\alpha$ )

1550 information of the small craters partially superposed by RMDSs, and their model ages

1551 measured from their morphologic analysis (Basilevsky, 1976; Figure 4) and the

1552 topographical diffusion model (Figure 5) used in this study.

\begin{tabular}{|l|l|l|l|l|l|l|l|}
\hline ID & Figure & $\begin{array}{l}\text { Crater } \\
\text { Center } \\
\text { Location } \\
\text { (Lon, } \\
\text { Lat) }\end{array}$ & $\begin{array}{l}\text { Crater } \\
\text { Diameter } \\
(\mathbf{D}, \mathbf{m})\end{array}$ & $\begin{array}{l}\text { Crater } \\
\text { depth } \\
\mathbf{( d ,}, \mathbf{m})\end{array}$ & $\begin{array}{l}\text { Maximum } \\
\text { Inner } \\
\text { slope } \\
\left(\alpha,{ }^{\circ}\right)\end{array}$ & $\begin{array}{l}\text { Degradation } \\
\text { age (Ma) by } \\
\text { Basilevsky } \\
(\mathbf{1 9 7 6})\end{array}$ & $\begin{array}{l}\text { Topographical } \\
\text { diffusion } \\
\text { model age } \\
\text { (Ma) in this } \\
\text { study }\end{array}$ \\
\hline 1 & $\begin{array}{l}\text { Fig. } \\
\text { 2a }\end{array}$ & $\begin{array}{l}27.451, \\
5.936\end{array}$ & $\sim 300$ & $\sim 15$ & $\sim 9$ & $750-1500$ & 770 \\
\hline 2 & $\begin{array}{l}\text { Fig. } \\
\text { 2b }\end{array}$ & $\begin{array}{l}-37.294, \\
-22.970\end{array}$ & $\sim 130$ & $\sim 4$ & $\sim 6-8$ & $160-320$ & 690 \\
\hline 3 & $\begin{array}{l}\text { Fig. } \\
2 \mathrm{c}\end{array}$ & $\begin{array}{l}52.393, \\
-1.456\end{array}$ & $\sim 300$ & $\sim 15$ & $\sim 9$ & $750-1500$ & 1000 \\
\hline 4 & $\begin{array}{l}\text { Fig. } \\
\text { 2d }\end{array}$ & $\begin{array}{l}34.187, \\
6.029\end{array}$ & $\sim 140$ & $\sim 7-9$ & $\sim 8-9$ & $200-300$ & 240 \\
\hline 5 & $\begin{array}{l}\text { Fig. } \\
\text { 2e }\end{array}$ & $\begin{array}{l}-27.224, \\
30.703\end{array}$ & $\sim 100$ & $\sim 5-6$ & $\sim 8-10$ & $200-300$ & 130 \\
\hline 6 & $\begin{array}{l}\text { Fig. } \\
\text { 2f }\end{array}$ & $\begin{array}{l}-27.083, \\
29.884\end{array}$ & $\sim 135$ & $\sim 5-7$ & $\sim 7-8$ & $200-300$ & 280 \\
\hline
\end{tabular}

1553 


\section{QAGUPUBLICATIONS}

Journal of Geophysical Research: Planets

Supporting Information for

The Lunar Mare Ring-Moat Dome Structure (RMDS) Age Conundrum:

Emplaced in the Copernican?

7 Feng Zhang ${ }^{1,2}$, James W. Head ${ }^{3}$, Christian Wöhler ${ }^{4}$, Alexander T. Basilevsky ${ }^{5}$, Lionel Wilson ${ }^{6}$,

$8 \quad$ Minggang Xie ${ }^{7}$, Roberto Bugiolacchi ${ }^{2}$, Thorsten Wilhelm ${ }^{4}$, Stephanie Althoff ${ }^{4}$, and Yong L. Zou ${ }^{1}$

$9{ }^{1}$ State Key Laboratory of Space Weather, National Space Science Center, Chinese Academy of Sciences, Beijing,

10 China; ${ }^{2}$ State Key Laboratory of Lunar and Planetary Sciences, Macau University of Science and Technology, Macau, 11 China; ${ }^{3}$ Department of Earth, Environmental and Planetary Sciences, Brown University, Providence, RI, USA; ${ }^{4}$ Image

12 Analysis Group, TU Dortmund University, Dortmund, Germany; ${ }^{5}$ Vernadsky Institute of Geochemistry and Analytical

13 Chemistry, Russian Academy of Sciences, Moscow, Russia; ${ }^{6}$ Lancaster Environment Centre, Lancaster University,

14 Lancaster, UK; ${ }^{7}$ College of Science, Guilin University of Technology, Guilin, China

16 Contents of this file

17

Figures $\mathrm{S} 1$ to $\mathrm{S} 10$

\section{Introduction}

The images were processed and investigated using the software ArcGIS 10.6.

23 Topography data and elevation measurements were derived from DTMs on LROC NAC

24 images/sets. 

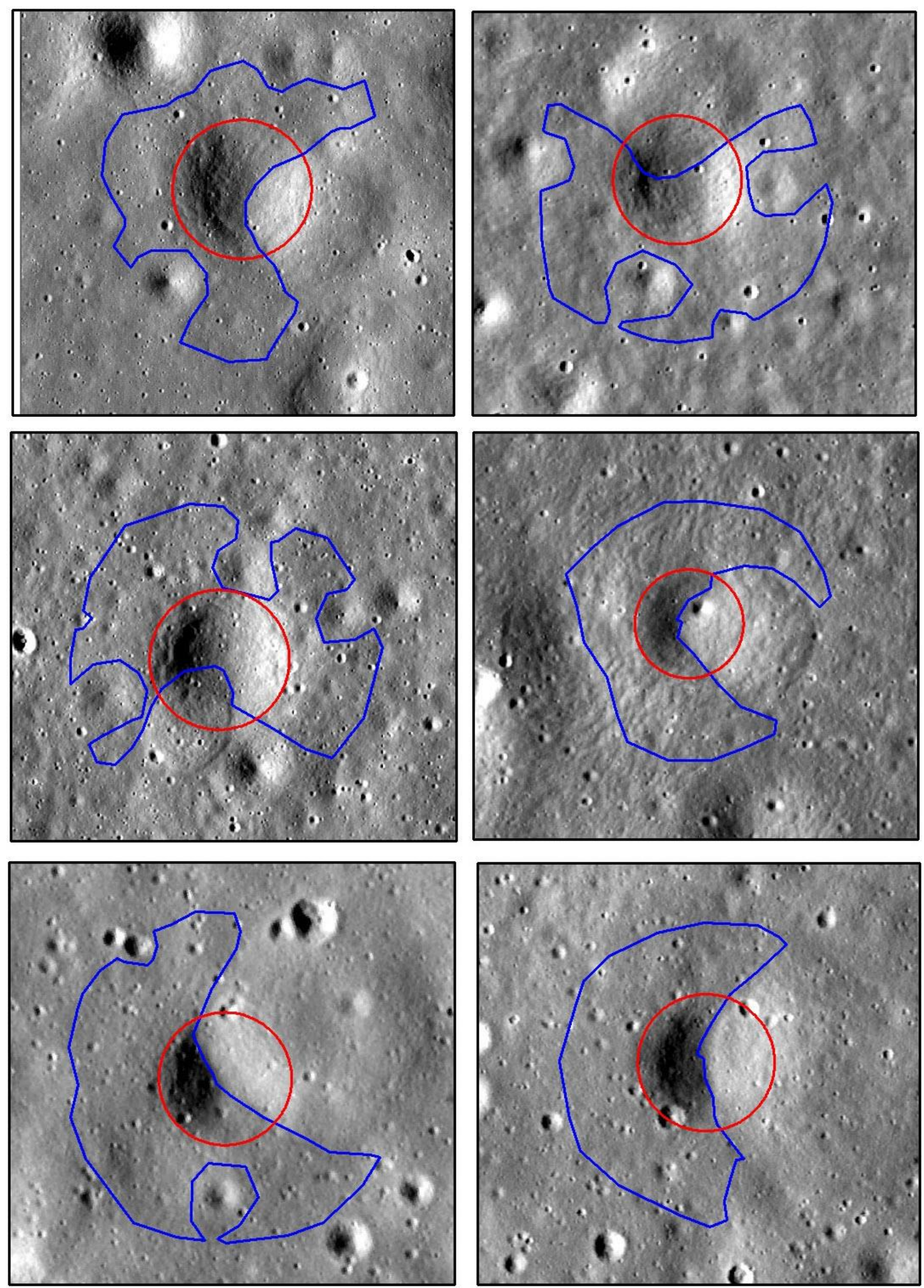

Figure S1: NAC images showing RMDS-superposed craters (Red circles). The pre-

29 impact surface is constructed by fitting a plane to the elevation data beyond 1.5 radii from

30 crater center. The regions used for the extraction of crater topography are shown in blue

31 polygons. 

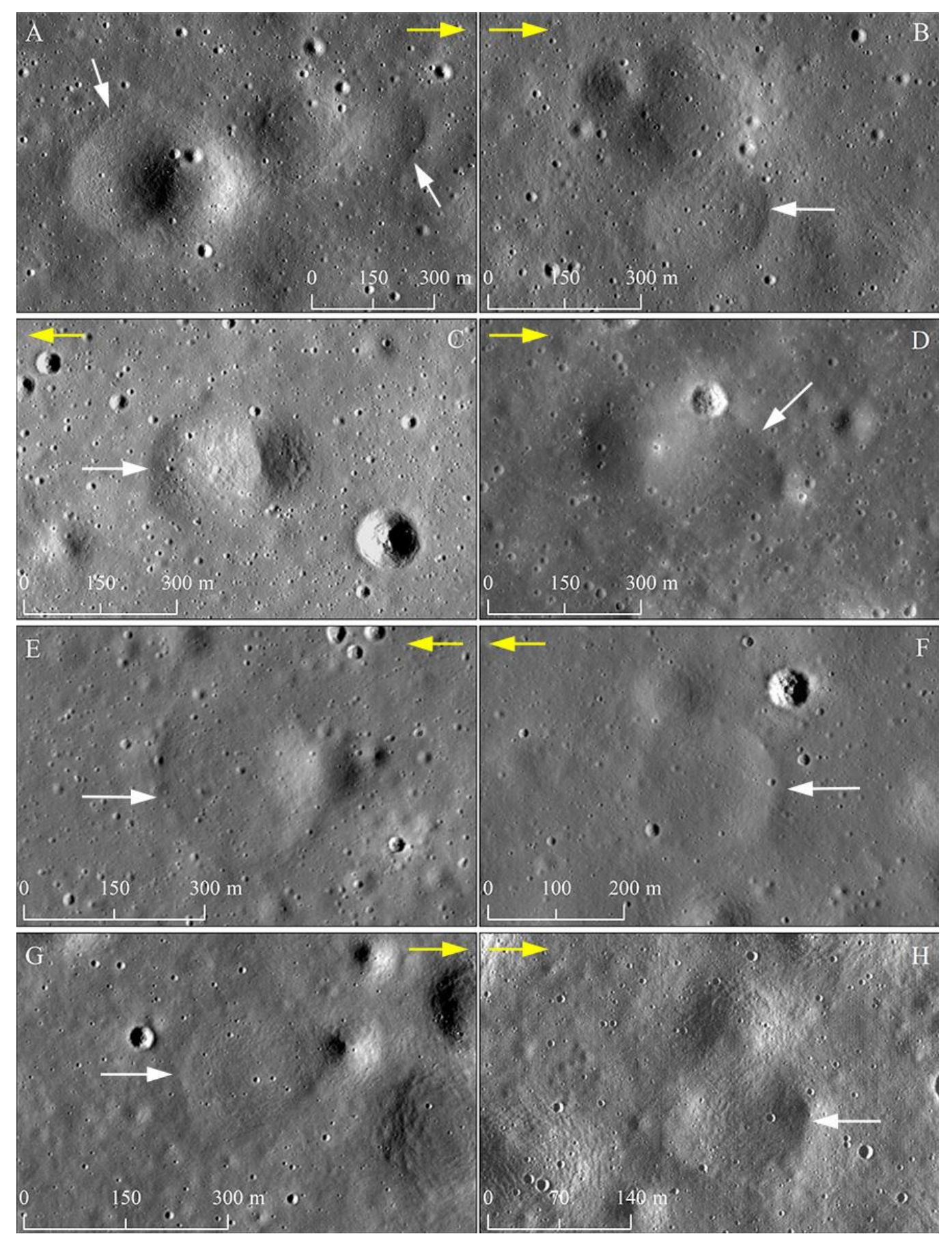

Figure S2: LROC NAC images for some candidate RMDS-crater overlap relationships.

(A) Location: $6.506^{\circ} \mathrm{N}, 34.177^{\circ} \mathrm{E}$; Tranquillitatis, NAC frame M180944663RE.

(B) Location: $8.276^{\circ} \mathrm{S}, 49.525^{\circ} \mathrm{E}$; Fecunditatis, NAC frame M1188038662RE.

(C) Location: $0.937^{\circ} \mathrm{S}, 52.398^{\circ} \mathrm{E}$; Fecunditatis, NAC frame M1245671393LE.

(D) Location: $0.234^{\circ} \mathrm{S}, 55.944^{\circ} \mathrm{E}$; Fecunditatis, NAC frame M183160424LE.

(E) Location: $29.288^{\circ} \mathrm{N}, 28.047^{\circ} \mathrm{W}$; Imbrium, NAC frame M1139086679LE.

(F) Location: $6.38^{\circ} \mathrm{S}, 40.459^{\circ} \mathrm{W}$; Procellarum, NAC frame M131914933RE.

(G) Location: $22.634^{\circ} \mathrm{S}, 38.306^{\circ} \mathrm{W}$; Humorum, NAC frame M1142688086RE.

(H) Location: $22.832^{\circ} \mathrm{S}, 38.091^{\circ} \mathrm{W}$; Humorum, NAC frame M133079100RE.

Yellow arrows point to sun illumination directions, while white arrows point to RMDSs. North is up in all figures. 

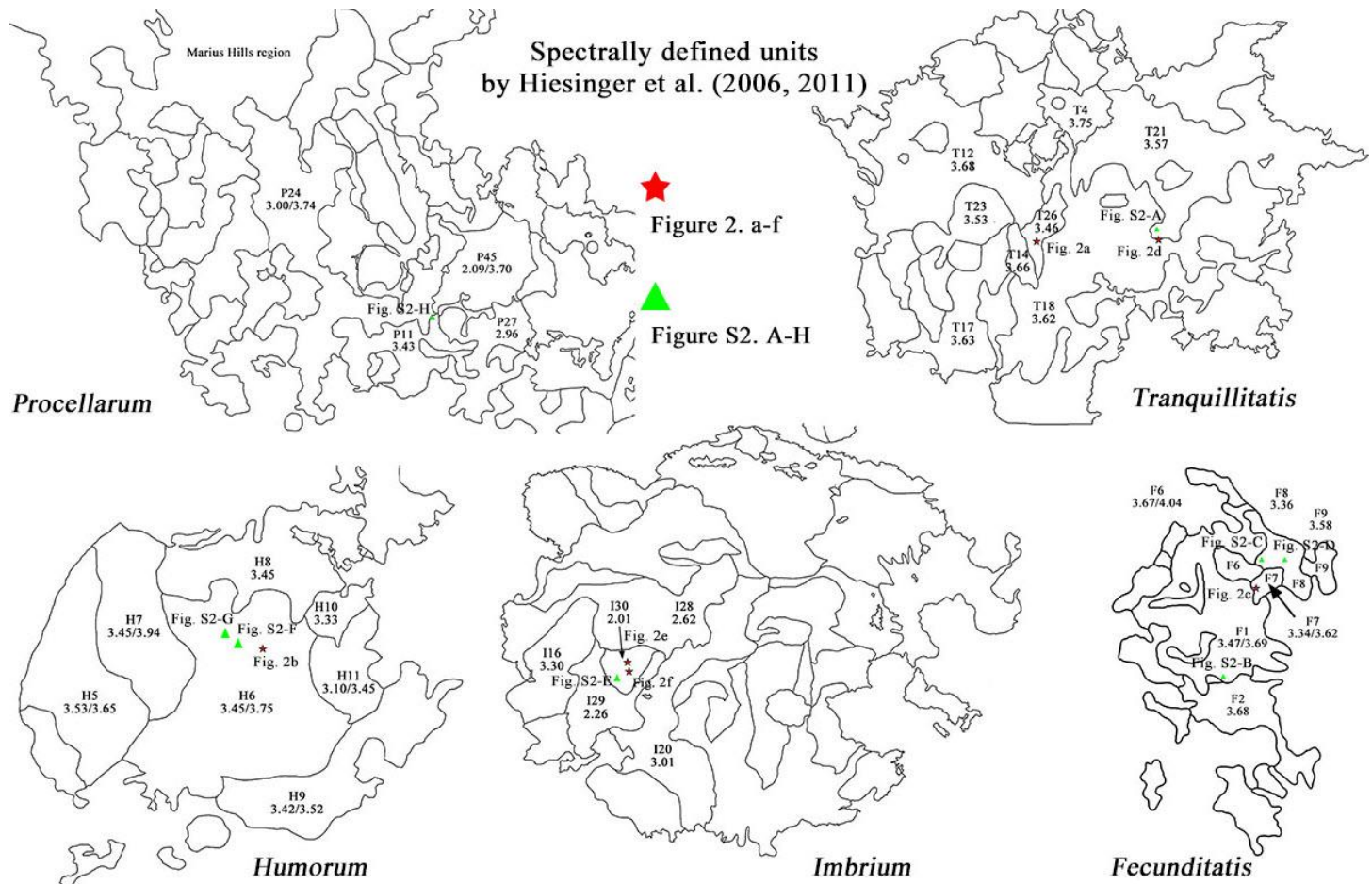

Figure S3: Distribution of RMDS-superposed craters on the nearside maria. Red stars represent the cases in Figure 1, while green triangles illustrate the cases in Figure S1. The black lines indicate spectrally defined units by Hiesinger et al. (2006, 2011). For some mare units hosting RMDS-superposed craters, their names and model ages (Hiesinger et al., 2006, 2011) by crater size-frequency measurement are labeled. Generally, these mare units containing the RMDSs shown in Figures 2 and S2 are of > 3.0 Ga in age, with an 

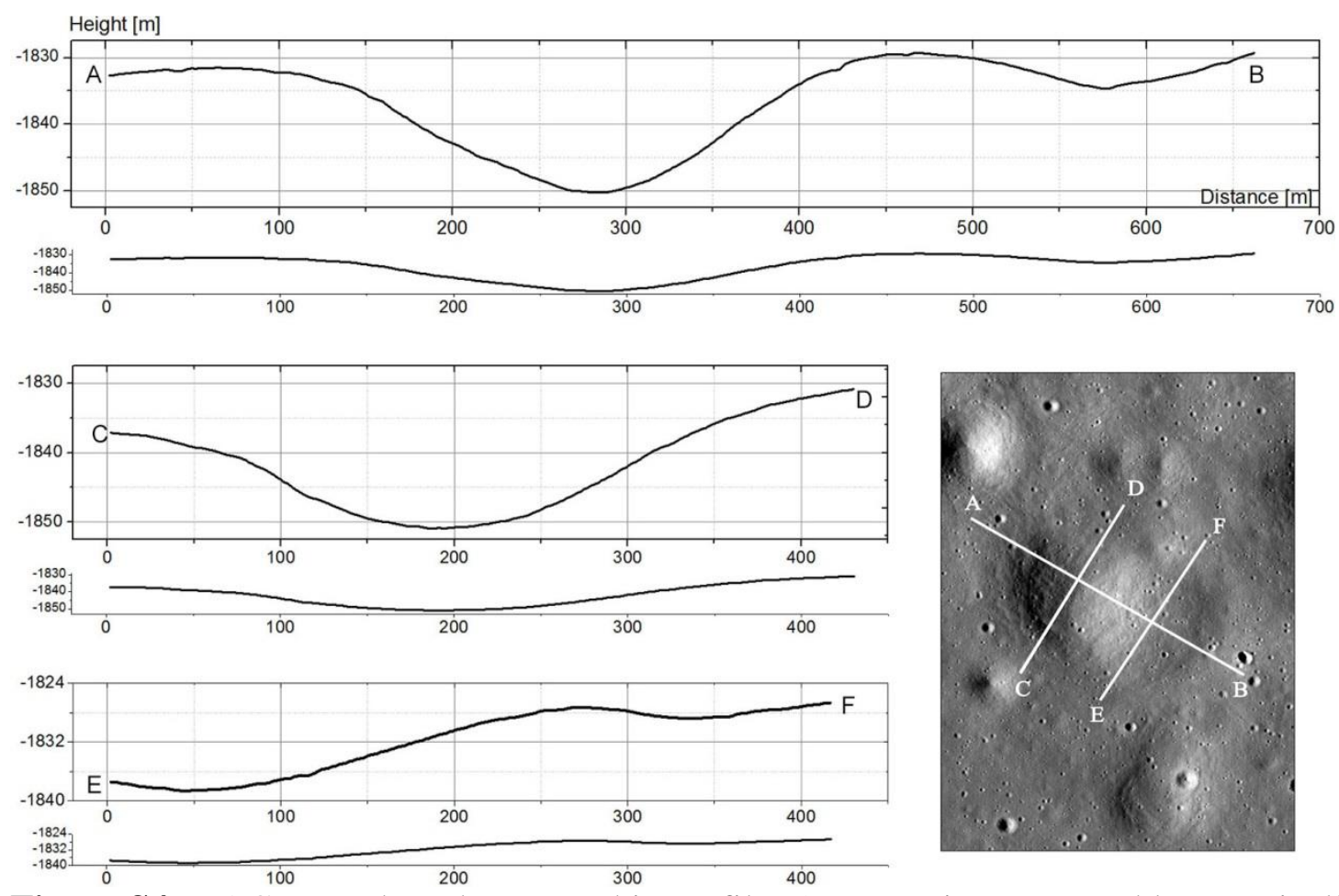

61 Figure S4: NAC-DEM based topographic profiles (a respective more and less vertically 62 exaggerated profiles) of the RMDS-superposed crater shown in Figure 2a.
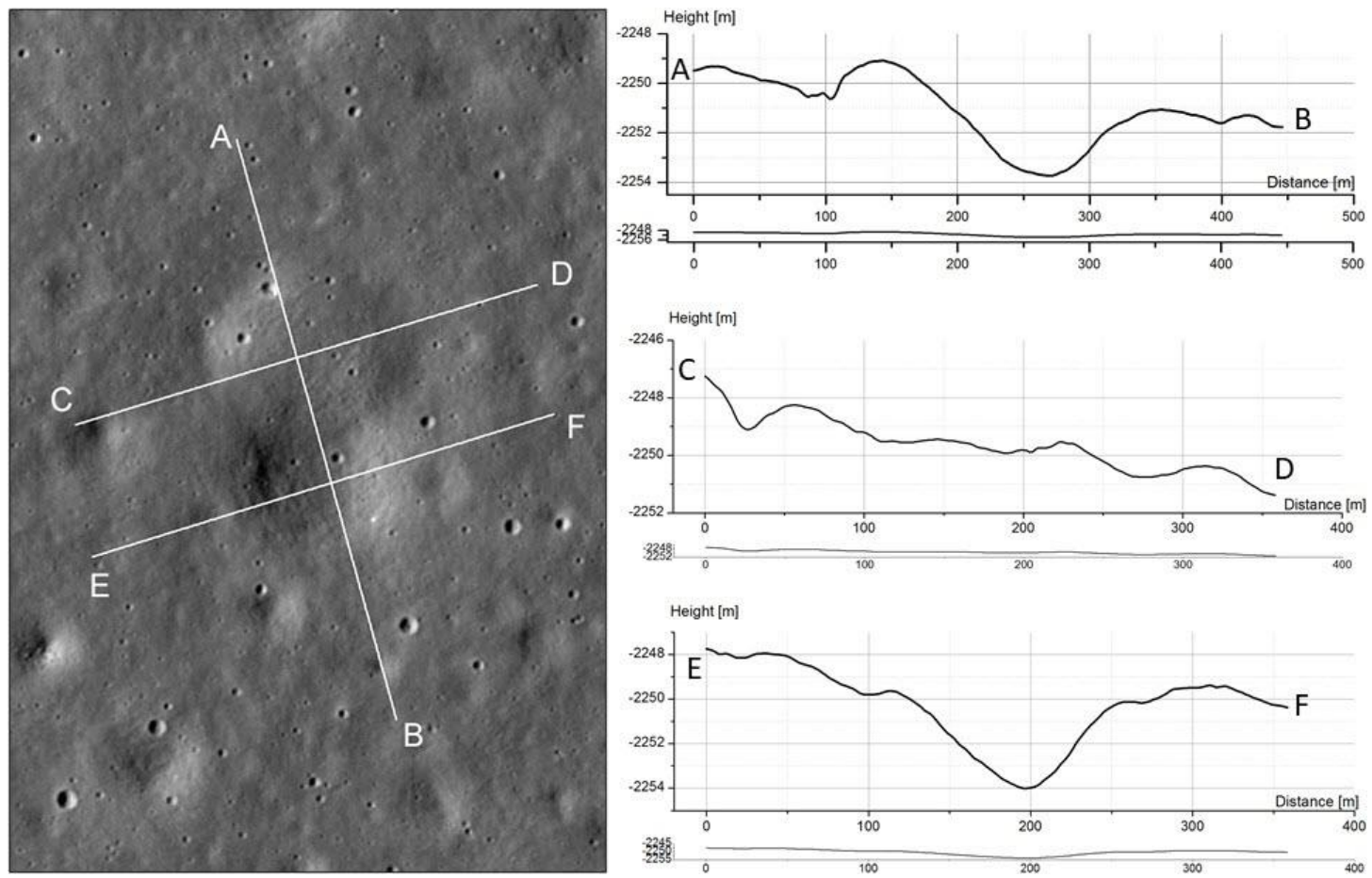

66 Figure S5: NAC-DEM based topographic profiles (a respective more and less vertically

67 exaggerated profiles) of the RMDS-superposed crater shown in Figure 2b. 

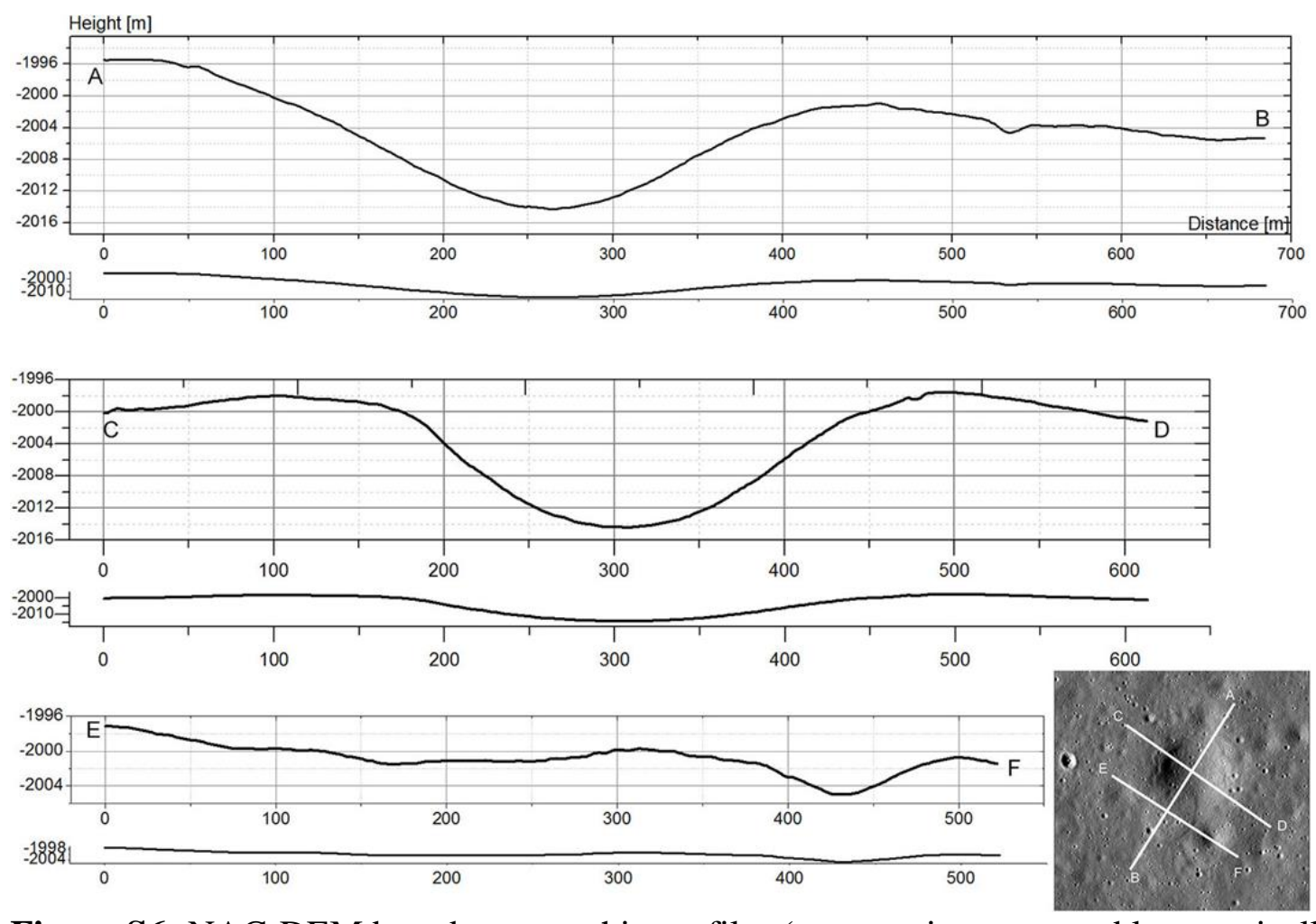

69 Figure S6: NAC-DEM based topographic profiles (a respective more and less vertically 70 exaggerated profiles) of the RMDS-superposed crater shown in Figure 2c. 

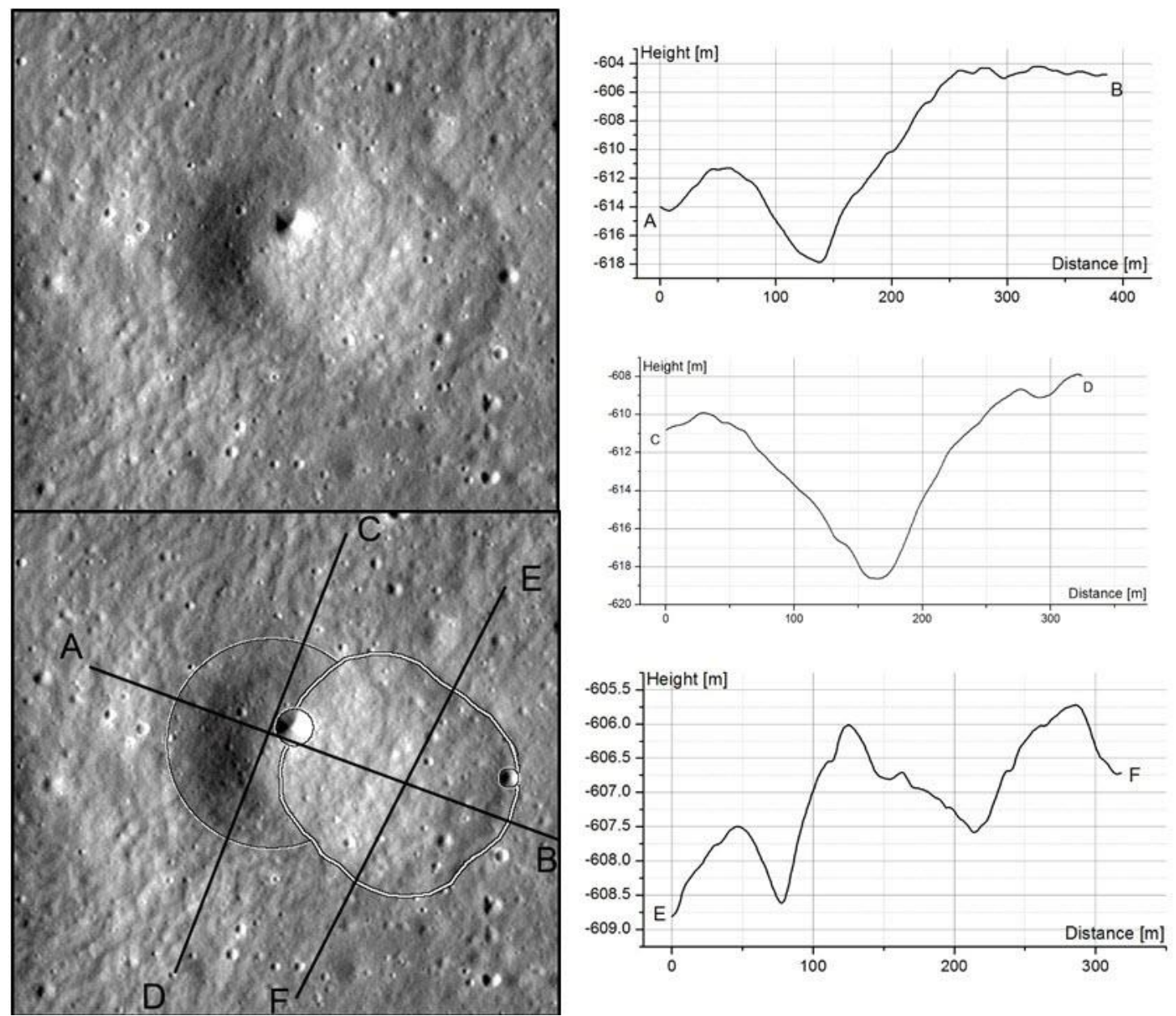

Figure S7: NAC-DEM based topographic profiles (a respective more and less vertically

73 exaggerated profiles) of the RMDS-superposed crater shown in Figure 2d. 

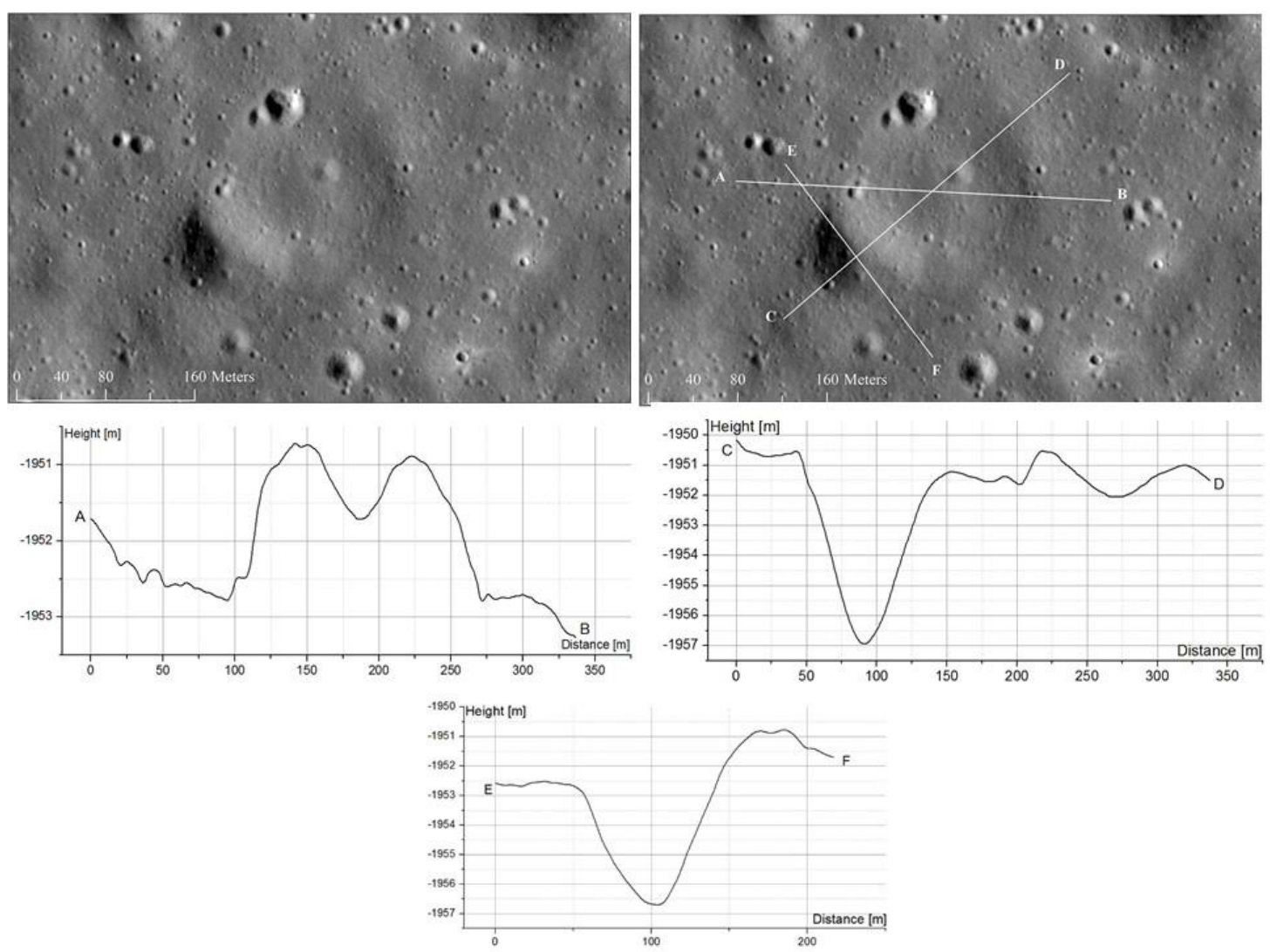

75 Figure S8: NAC-DEM based topographic profiles (a respective more and less vertically 76 exaggerated profiles) of the RMDS-superposed crater shown in Figure 2e. 

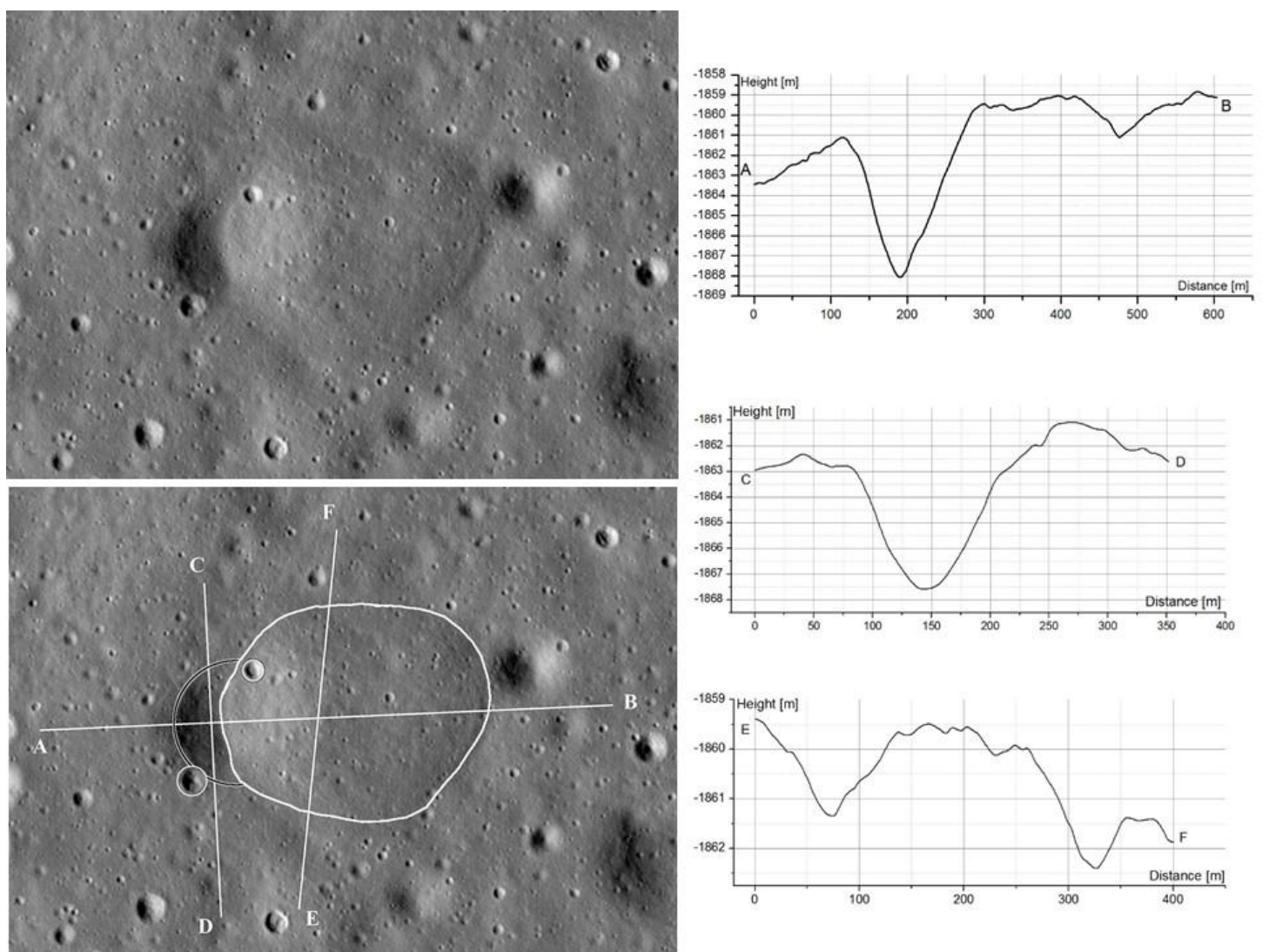

78 Figure S9: NAC-DEM based topographic profiles (a respective more and less vertically 79 exaggerated profiles) of the RMDS-superposed crater shown in Figure $2 \mathrm{f}$. 


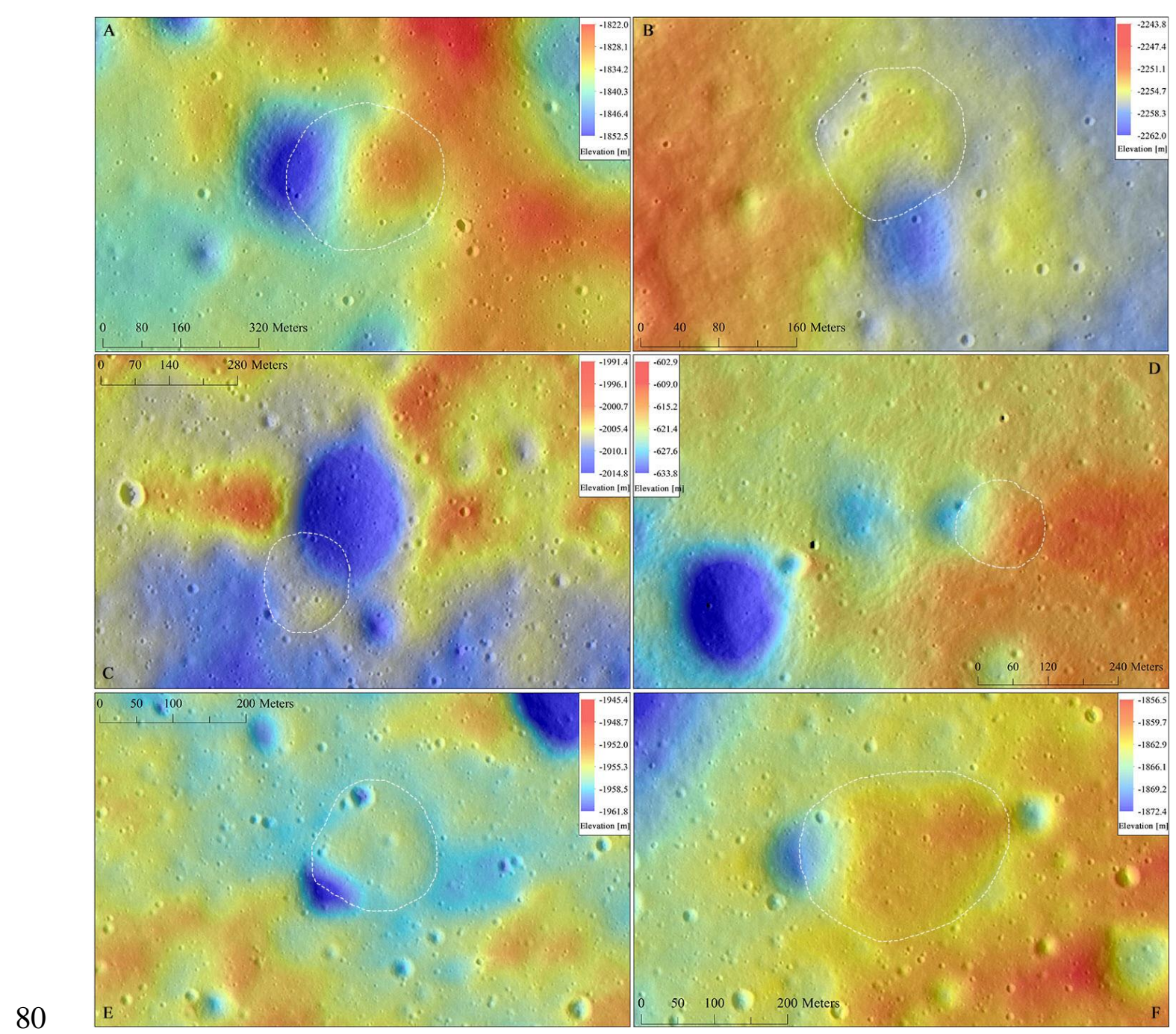

81 Figure S10: LROC NAC-derived 2 m/pixel DTM for each of RMDS-superposed crater

82 used in this study. An approximate outline of each RMDS is illustrated by dashed white

83 line in each subfigure. NAC image pairs used to construct DTMs are included: (A)

84 M1172873803LE and RE; (B) M1142680981LE and RE; (C) M1126787189LE and RE;

85 (D) M180944663LE and RE; (E) and (F) M181352550LE and RE. 